\title{
Influence of injection pressure on the thermohydrodynamic behavior of tilting pad
} journal bearings - Model and Experiment

\author{
Bizarre, L.; Daniel, G. B.; Santos, I. F.; Cavalca, K. L.
}

Published in:

Tribology Transactions

Link to article, DOI:

$10.1080 / 10402004.2020 .1862945$

Publication date:

2021

Document Version

Peer reviewed version

Link back to DTU Orbit

Citation (APA):

Bizarre, L., Daniel, G. B., Santos, I. F., \& Cavalca, K. L. (2021). Influence of injection pressure on the thermohydrodynamic behavior of tilting pad journal bearings - Model and Experiment. Tribology Transactions, 64(3), 513-527. https://doi.org/10.1080/10402004.2020.1862945

\section{General rights}

Copyright and moral rights for the publications made accessible in the public portal are retained by the authors and/or other copyright owners and it is a condition of accessing publications that users recognise and abide by the legal requirements associated with these rights.

- Users may download and print one copy of any publication from the public portal for the purpose of private study or research.

- You may not further distribute the material or use it for any profit-making activity or commercial gain

- You may freely distribute the URL identifying the publication in the public portal 


\section{Influence of injection pressure on the thermohydrodynamic behavior of tilting pad journal bearings - Model and Experiment.}

\section{Bizarre , G. B. Daniel , I. F. Santos \& K. L. Cavalca}

To cite this article: L. Bizarre , G. B. Daniel , I. F. Santos \& K. L. Cavalca (2020): Influence of injection pressure on the thermohydrodynamic behavior of tilting pad journal bearings - Model and Experiment., Tribology Transactions, DOI: $10.1080 / 10402004.2020 .1862945$

To link to this article: https://doi.org/10.1080/10402004.2020.1862945

Accepted author version posted online: 14 Dec 2020.

Submit your article to this journal $₫$

Q View related articles $\sqsubset$

View Crossmark data $\nearrow$ 


\title{
Corrections indications
}

\section{Influence of injection pressure on the thermohydrodynamic behavior of tilting pad journal bearings - Model and Experiment.}

\author{
L. Bizarre ${ }^{a}$, G. B. Daniel ${ }^{a}$, I. F. Santos ${ }^{b}$, K. L. Cavalca ${ }^{a}$ \\ ${ }^{a}$ Department of Integrated Systems, University of Campinas, Campinas, São Paulo, \\ Brazil; ${ }^{b}$ Department of Mechanical Engineering, Technical University of Denmark,
} Kogens-Lyngby, Denmark

*E-mail: leticia.bizarre@fem.unicamp.br (L. Bizarre)

In rotating machines, tilting pad bearings (TPJBs) are widely used due to their enhanced design stability in comparison with alternative bearing configurations. In the present research, a thermohydrodynamic (THD) lubrication model for a tilting pad bearing with injection is developed. Within the THD lubrication model, the lubricant is also fed into each pad through a central injection orifice. The effects on the lubricant oil film pressures and temperatures and subsequent influences on the system dynamic behavior were investigated. Another important factor considered within the THD model is associated with the flexibility of the pivot of each pad and its impact on the behavior of the bearing when subjected to direct lubricant injection. The numerical model results are compared with the measurements of the rotor equilibrium position within the bearing and the pad temperatures obtained from the test rig designed specifically for the TPJB geometry with and without central pad injection. Pad temperatures are measured before the injection orifice position and after it. Agreement between experimental and model-predicted results provides confidence in the model's ability to evaluate the dynamic behavior of the bearing and its effect on the complete system through the stiffness and damping coefficients.

Keywords: tilting pad bearing, thermohydrodynamic model, direct active lubrication, experimental validation. 


\section{Nomenclature}

\begin{tabular}{|c|c|}
\hline $\mathrm{BC}$ & Boundary Condition \\
\hline FVM & Finite Volume Method \\
\hline LOP & Load On Pad \\
\hline TEHD & Thermoelastohydrodynamic \\
\hline THD & Thermohydrodynamic \\
\hline TPJB & Tilting Pad Journal Bearing \\
\hline$\alpha$ & Pad angle deflection $\left[{ }^{\circ}\right]$ \\
\hline$\beta_{s}$ & Pad arc length $\left[^{\circ}\right]$ \\
\hline$\varepsilon$ & Eccentricity ratio $[-]$ \\
\hline$\mu$ & Oil dynamic viscosity [Pa.s] \\
\hline$v_{\text {oil }}$ & Oil kinematic viscosity [ctS] \\
\hline$\rho$ & Oil density $\left[\mathrm{Kg} / \mathrm{m}^{3}\right]$ \\
\hline$\omega$ & Journal angular velocity $[\mathrm{rad} / \mathrm{s}]$ \\
\hline$\varphi_{j}$ & Angle between the inertial system and the auxiliary system for the $\mathrm{j}$-th pad $\left[^{\circ}\right]$ \\
\hline$\Phi$ & Viscous dissipation $\left[\mathrm{W} / \mathrm{m}^{3}\right]$ \\
\hline$C_{f}$ & Oil specific heat capacity $[\mathrm{J} /(\mathrm{Kg} . \mathrm{K})]$ \\
\hline$C_{p}$ & Machined radial clearance of the bearing $[\mathrm{m}]$ \\
\hline$C_{b}$ & Assembled radial clearance of the bearing $[\mathrm{m}]$ \\
\hline$d_{0}$ & Injection orifice diameter $[\mathrm{m}]$ \\
\hline$e$ & Eccentricity $[\mathrm{m}]$ \\
\hline$f_{\text {static }}$ & Static force on frame extremity $[\mathrm{N}]$ \\
\hline$f_{\text {pivot }}$ & Reaction force from pivot point $[\mathrm{N}]$ \\
\hline$h$ & Oil film thickness $[\mathrm{m}]$ \\
\hline$h_{s}$ & Pad thickness $[\mathrm{m}]$ \\
\hline$k_{f}$ & Oil thermal conductivity $[\mathrm{W} /(\mathrm{m} . \mathrm{K})]$ \\
\hline$K_{\text {pivot }}$ & Pivot point stiffness $[\mathrm{N} / \mathrm{m}]$ \\
\hline$L$ & Bearing length $[\mathrm{m}]$ \\
\hline$l_{0}$ & Injection tube length $[\mathrm{m}]$ \\
\hline$l_{1}$ & Distance to center of journal measured from $O_{1}[\mathrm{~m}]$ \\
\hline$l_{2}$ & Distance to end of frame measured from $O_{1}[\mathrm{~m}]$ \\
\hline$m$ & Mass of journal and frame $[\mathrm{Kg}]$ \\
\hline
\end{tabular}




\begin{tabular}{|l|l|}
\hline$m_{p}$ & Preload factor [-] \\
\hline$O_{1}$ & Frame rotational point [-] \\
\hline$O_{2}$ & Journal rotational point [-] \\
\hline$O P$ & Pivot center of rotation [-] \\
\hline$O S$ & Pad center [-] \\
\hline$O E$ & Shaft center [-] \\
\hline$P$ & Pressure in the oil film between journal and pad [Pa] \\
\hline$P_{\text {inj }}$ & Injection pressure [m] \\
\hline$R$ & Journal radius [m] \\
\hline$R_{S}$ & Pad radius [m] \\
\hline$S$ & Sommerfeld number [-] \\
\hline$t$ & Time [s] \\
\hline$T$ & Temperature [ ${ }^{\circ}$ ] \\
\hline$T_{\text {inj }}$ & Injection temperature [ $\left.{ }^{\circ} \mathrm{C}\right]$ \\
\hline$U$ & Journal surface velocity [m/s] \\
\hline$u, v, W$ & Linear velocities in $\mathrm{x}-, \mathrm{y}-$ and $\mathrm{z}-\mathrm{direction}[\mathrm{m} / \mathrm{s}]$ \\
\hline$W$ & Load on bearing [N] \\
\hline$X, Y, Z$ & Inertial coordinate system [-] \\
\hline$x, y, Z$ & Local coordinates system \\
\hline$x^{\prime}, y^{\prime}, z^{\prime}$ & Mobile with the pads coordinate system \\
\hline & \\
\hline & \\
\hline & \\
\hline & \\
\hline
\end{tabular}

\section{INTRODUCTION}

The components of rotating machines are generally designed and manufactured by a purely deterministic mechanical design approach based on critical operating conditions.

Under such circumstances, a conventionally designed component can meet operation demands neglected in the design phase, however, its adaptive capacity to extreme operating conditions is often limited.

Industrial segments involving the extraction, conversion and generation of energy demand ever-growing productivity and performance from rotating machines, which often points to innovative ways of designing and operating some critical system components. Rotating machines employed in the energy sector increasingly require 
bearings designed for high performance, often with the active capacity to adapt to different operating conditions. In rotating machinery applications involving high loads and high rotating speeds, fluid film bearings are a natural selection to meet the design requirements. A wide range of design configurations is available to accommodate different operational demands and costs/benefits of the application.

This study focuses on a specific configuration of a radial fluid film bearing with variable geometry, known as tilting pad bearing. Widely applied in turbomachines, TPJBs are known to remarkably enhance rotor stability compared with other hydrodynamic bearing designs. TPJB designs effectively eliminate the cross-coupled forces typical of hydrodynamic fixed geometry bearings and which give rise to the wellknown phenomenon of fluid-induced instability [1, 2].

The current design and application of TPJBs have resulted from more than 60 years of accumulated knowledge regarding their dynamic and static characteristics. A seminal achievement related to modeling of TPJB dynamic behavior was the approach to the equivalent linearized coefficients of tilting pads obtained by Lund [3] and deeply discussed by Nicholas [4]. The linearized TPBJ dynamic model was subsequently expanded by Allaire [5] to explicitly include the contribution from the additional degrees-of-freedom of the pads. The investigations [3, 5] facilitated the link between TPJBs and the dynamic behavior of the rotating system. In order to evaluate rotor unbalance response, it has been shown [6] that synchronously reduced coefficients from TPJBs can be employed, whereas for rotor stability analysis, full bearing coefficients must be used.

Dimond et al. [7] presented an extensive review of research investigations focused on experimental validation of the linearized dynamic coefficients predicted from the aforementioned models and their variants. These experimental validation 
efforts are likewise reflected in Refs. [8, 9, 10 and 11]. During experimental investigations of TPJBs, it was noticed that the accurate prediction of the static equilibrium position of the rotor within the bearings was critical for the accurate prediction of the linearized dynamic coefficients. The static equilibrium position was influenced by nonlinear interaction between the fluid film, pad flexibility, and flexibility of the pad pivot. Subsequent models $[12,13,14]$ were considered more accurate with the inclusion of the flexibility of the pad pivot and the pad itself. Additionally, Fillon et al. [15], Earles et al. [16, 17] and Kim et al. [18] developed thermoelastohydrodynamic (TEHD) models of TPJBs and studied how thermal effects affects TPJB performance under certain operating conditions.

Raud et al. [19] performed a numerical modeling study of hydrostatic conditions of tilting-pad bearings with the application of lift pockets, seeking applications at low speed and highly loaded tilting pad journal bearings. An increase in oil film thickness and a reduction in the maximum pressure occurred with the lift pockets application.

Hagemann et al. [20] studied tilting-pad journal bearings with jacking-oil devices under three different operation conditions: hydrostatic, hybrid, and hydrodynamic operation. The experimental and numerical data reveal that the additional jacking-oil gives a considerable increase of load-carrying capacity and the misalignments and manufacturing tolerances can directly impact the lift-off pressures and vertical lift displacements.

Still considering the application of hydrostatic jacking mechanisms, Buchhorn et al. [21] perform theoretical and experimental investigation varying the hydrostatic pressure, increasing the lubricant viscosity due to the injection of cold oil, decreasing the temperature gradients and, consequently, the thermal pad deformation. The authors 
concluded that load-carrying increase is not mostly based on the hydrostatic pressure component, since the decreased pad deformations make the largest contribution.

Direct lubrication on the pad sliding surface can be used to provide a certain pressure level on the sliding surface or to minimize bypass flow of the lube oil. Considering the injection of cooling fluid, the Leading Edge Groove (LEG) tilting-pad system is widely applied. Yang et al [22] studied numerically and experimentally a three-pad (LEG) tilting to investigate the bearing dynamic properties. The comparison of the theoretical and experimental results showed that the bearings have good stiffness and damping characteristics, mainly in the load application direction. Brockweel et al. [23] developed their research on the performance of the LEG tilting-pad journal bearing, analyzing the power loss and the higher pad temperature for the conventional tilting-pad and the LEG bearings. A reduction in these parameters for the LEG bearing was noticed and also a comparison on the effects for Load on Pad and Load between Pads configuration.

Building upon the pioneering work of Ulbrich and Althaus [24] in the application of active control to rotating systems, Santos [25] developed active control approaches for TPJBs based on hydraulic actuation of the chambers behind the tilting pads as well as by active radial injection into the bearing lubricant film. In a passive mode, radial injection of lubricating fluid through a central circular orifice within a bearing pad can modify the developing oil film to improve static load carrying-capacity, reduce temperatures, and improve dynamic performance. Further performance enhancement occurs when the radial lubricant injection functions as an actuation mechanism within an active control strategy.

Santos and Russo [26] presented a modified Reynolds equation which incorporated the radial injection of lubricant into the TPJB pads. The modified 
Reynolds equation predicted the static and dynamic performance of TPJBs with radial injection under isothermal conditions. Santos and Nicoletti [27] subsequently extended the modified Reynolds equation model to include thermal effects within the fluid film through the solution of a thin-film energy equation. Haugaard and Santos [28] presented a model for the TPJB with radial injection considering pad and pad pivot flexibility captured through a linear elastic finite element model. Santos [29] proved the feasibility of radial injection to improve TPJB performance through experimental validation of the model-predicted results.

Chang et al [30] applied the Newton-Raphson method to predict the bearing characteristics of the hydrodynamic pressure, the eccentricity, and the pad attitude angles for tilting pad bearings numerical model under TEHD lubrication. For the energy equation solution, 3D heat transfer equations for pads were solved using a sequential sweeping method, and the elastic deformation and thermal expansion applied the finite element method. It was possible to conclude that the elastic deformation generated by hydrodynamic pressure and the influence of the temperature elevation perform a significant role in the calculated bearing system.

Regarding the pad pivot flexibility, Nilsson [31] noted its significant impact on the dynamic TPJB performance. San Andres et al. [32] reviewed the influence of pad pivot flexibility on the predicted static and dynamic performance of TPJBs by comparing it with the experiments of Gaines [33]. Suh and Choi [34] researched the effects of the angular misalignment of the pad on bearing performance considering a THD lubrication model.

The investigations of Daniel and Cavalca [35] extended the model of Santos and Russo [26] and Santos and Nicoletti [27] by accounting for the 3D temperature distribution within the TPJB oil film, but in the absence of radial injection. Stiffness and 
damping coefficients were calculated from the hydrodynamic and thermohydrodynamic lubrication models, verifying the influence of the thermal effects on the dynamic characteristics of the TPJBs. Following the modelling of Daniel and Cavalca [35], Bizarre et al. [36] included the effect of pivot flexibility and evaluated the behaviour of temperature, pressure and eccentricity ratio of tilting-pad bearing comparing with experimental results.

The present study extends the TPJB model described in Daniel and Cavalca [35] with the addition of radial lubricant injection into the bearing film and consideration of the pad pivot flexibility $[32,33]$. The influence of these effects on the rotor static equilibrium position, the temperature distribution, and the equivalent dynamic coefficients of the TPJB are assessed. A specific tilting-pad test rig was applied to investigate the effects in the tilting-pad bearing under nominal operational conditions. The crucial characteristic of the test rig is practically to isolate all the effects in the vertical direction from the horizontal direction. This assembly mitigates any effects in a horizontal direction. Hence, the apparatus enables to compare experimental results with an analysis of each pad design separately taken into account the THD lubrication of the oil film, the pad pivot flexibility boundaries and the direct oil injection effect on temperature decay. Experimental tests were performed to evaluate the behavior of the tilting pad bearing under direct injection on the pads center and the measured data were compared with the results obtained in the proposed numerical model. The experimental validation of the static equilibrium position of the rotor and the bearing pad temperatures reveals promising results of the theoretical model, giving good predictions for application in rotor bearing systems.

\section{METHODOLOGY}


This study assesses the behavior of a tilting pad bearing under thermohydrodynamic (THD) lubrication considering flexible pad pivots and oil injection in the center of the pads (central orifice). Pressure and temperature maps, oil film thickness, shaft equilibrium position and dynamic coefficients are evaluated to quantify performance. The THD model energy equation considers the variation of the temperature across the thin lubricant film. In the subsequent sections, the THD model theory and numerical solution are described along with the experimental test-rig used for validation of the developed model.

\subsection{Theoretical model description}

\subsubsection{Tilting pad with THD lubrication and oil injection on the pad}

The tilting pad journal bearing (TPJB) studied in this research has the purpose of representing the bearing in the experimental test rig described in section 2.2. In the test rig, two pads are supported by a flexible pivot made of steel and the shaft load is applied in the middle of the pad (LOP -load-on-pad configuration). Figures 1 (a) and (b) show the shaft radius $(R)$, the pad radius $\left(R_{S}\right)$, the assembled radial clearance of the bearing $\left(C_{b}\right)$, the angular coordinate on the pad $(\beta)$, the pivot position $(\varphi)$ in the inertial reference system $(X, Y, Z)$, the centers of the shaft $(O E)$ and pad $(O S)$, the pad thickness $\left(h_{s}\right)$, the pad arc $\left(\beta_{s}\right)$, the pad length $(L)$, the local coordinate system $\left(x_{p}, y_{p}, z_{p}\right)$ and the auxiliary reference system fixed to pad $\left(x_{p}^{\prime}, y_{p}^{\prime}, z_{p}^{\prime}\right)$, while Figure 1 (d) shows the coordinate system fixed at the pad corner used during the numerical discretization of the oil film $(x, y, z)$

\section{Figure 1}

Figure $1(\mathrm{c})$ shows the shaft eccentricity $(e)$ associated with the static equilibrium position of the shaft. The injection orifice located in the middle of the pads and the 
injection supply tube are shown in Figure 1 (d). The parameters labeled in Figure 1 (d) are the diameter of the injection orifice $\left(d_{0}\right)$, the length of the injection tube $\left(l_{0}\right.$, in this work, is the same as pad thickness) and the center of the injection orifice $\left(C_{h}\right)$ described by the coordinates $x_{0}$ and $z_{0}$. Figure 1 (e) brings a schematic representation of the bearing housing used during the present work with the pivot details, pads, shaft and holes indication for replacement oil and direct injection on pads.

Figure 2

Considering the TPJB geometrical characteristics, the hydrodynamic pressure $\mathrm{P}(\mathrm{x}, \mathrm{Z})$ which develops in the gap between the rotor and the bearing pad can be determined from the modified Reynolds equation as presented by Dowson [37] at each time step, considering the injection velocity term, see [25-26]:

$$
\frac{\partial}{\partial x}\left(F_{2} \frac{\partial P}{\partial x}\right)+\frac{\partial}{\partial z}\left(F_{2} \frac{\partial P}{\partial z}\right)=U \frac{\partial}{\partial x}\left[h-\frac{F_{1}}{F_{0}}\right]+\frac{\partial h}{\partial t}+V_{i n j}
$$

considering,

$$
F_{1}=\int_{0}^{h} \frac{y}{\mu} d y, F_{2}=\int_{0}^{h} \frac{y}{\mu}\left(y-\frac{F_{1}}{F_{0}}\right) d y \text { and } F_{0}=\int_{0}^{h} \frac{1}{\mu} d y
$$

where $\mu$ is the oil viscosity, $h$ is the oil film thickness, $\omega$ is the shaft rotational speed, $t$ is time, $V_{i n j}$ is the radial injection velocity and $x$ and $z$ are the Cartesian coordinates.

As described in Santos and Russo [26], the injection velocity profile can be approximated by considering fully-developed Hagen-Poiseuille flow with the pressure gradient approximated using the injection pressure $\left(P_{i n j}\right)$, the film pressure $(P(x, z))$ and the injection tube length $\left(l_{0}\right)$

$$
V_{i n j}=\frac{1}{4 \mu_{i n j} l_{0}}\left(P(x, z)-P_{i n j}\right)\left(\frac{d_{0}^{2}}{4}-\left(x-x_{0}\right)^{2}-\left(z-z_{0}\right)^{2}\right)
$$

The oil film thickness function varies with the angular displacement of the pad, the shaft position $\left(x_{s}\right.$ and $\left.y_{s}\right)$, and the geometric parameters [26] is

$$
h(\beta)=R_{S}-R-\left\{\sin (\beta)\left[y_{S}+\alpha\left(R_{S}+h_{S}\right)\right]+\cos (\beta)\left(x_{S}+R_{S}-R-C_{b}\right)\right\}
$$


To consider the temperature distribution in the oil film, an energy equation must be solved in addition to the Reynolds equation for the pressure. Heat transfer in the axial (z) direction can be neglected regarding radial and circumferential coordinates of the bearing, according to Cameron [38]. Thus, with the previous considerations, Equation 5 is the thin-film energy equation, where $T(x, y)$ is the temperature distribution, $\Phi$ is the viscous dissipation of the fluid film (Equation 6), $\rho$ is the oil density, $\mu$ is the oil film viscosity, and $u, v$ and $w$ are the linear fluid velocities in $x, y$ and $z$ directions, respectively.

$$
\begin{gathered}
h \rho C_{f}\left(u \frac{\partial T}{\partial x}+v \frac{\partial T}{\partial y}\right)=k_{f}\left(\frac{\partial^{2} T}{\partial x^{2}}+\frac{\partial^{2} T}{\partial y^{2}}\right)+\mu \Phi \\
\Phi=2\left[\left(\frac{\partial u}{\partial x}\right)^{2}+\left(\frac{\partial v}{\partial y}\right)^{2}\right]+\left(\frac{\partial u}{\partial y}+\frac{\partial v}{\partial x}\right)^{2}+\left(\frac{\partial w}{\partial x}\right)^{2}+\left(\frac{\partial w}{\partial y}\right)^{2}
\end{gathered}
$$

The Cartesian velocity components $(u, v, w)$ required in the energy equation can be evaluated as [39]

$$
\begin{gathered}
u=\frac{1}{\mu}\left(\frac{\partial P}{\partial x} \frac{y^{2}}{2}+\left(\frac{\mu \omega R}{h}-\frac{\partial P}{\partial x} \frac{h}{2}\right) y\right) \\
v=\frac{\partial h}{\partial t} \frac{y}{h}+V_{i n j}\left(1-\frac{y}{h}\right) \\
w=\frac{1}{2 \mu} \frac{\partial P}{\partial z}\left(y^{2}-h y\right)
\end{gathered}
$$

Walther's formula $[40,41]$ is applied to describe the viscosity dependence on the temperature (Equation 10) and its terms are: $v_{\text {oil }}$, the kinematic viscosity, and A and B are two oil-specific constants. In Equation 10, the kinematic viscosity has units of centistokes and $T_{\text {oil }}$ has degrees-Celsius. The oil used in the experimental tests and applied in numerical simulations was the ISO VG22, with constants $A=23.16$ and $\mathrm{B}=3.84$. The viscosity of the injection oil $\left(\mu_{i n j}\right)$ was calculated using the same relation of Equation 10 considering the temperature of the oil during the injection $\left(T_{\text {inj }}\right)$.

$$
\log \left[\log \left(v_{o i l}+0.6\right)\right]=A-B \cdot \log \left(T_{o i l}\right)
$$




\subsubsection{Pivot Flexibility}

As previously mentioned, the experimental test rig has a tilting pad bearing with two pads, with each pad supported by a central pivot made of steel. The flexibility of these pivots is modeled through linear stiffness coefficients. Figure 2 (b) contains a schematic including the pivot stiffness $\left(K_{\text {pivot,1,2 }}\right)$ within the mechanical model of the bearing system. To account for the pad pivot flexibility, an additional deflection is added to the iteratively updated oil film thickness (Equation 11) as

$$
h_{t}(\beta)=h(\beta)+\delta_{\text {pivot }}
$$

\subsubsection{Equilibrium position and dynamic coefficients}

The rotor static equilibrium position in the bearing is achieved when the static force and moment balance (Equations 12-17) for the TPJB system are satisfied. The terms presented in this system are: $\delta_{m j}$ for the deformation of the pivot $j, j$ represents the j-th pad, $N$ the number of pads, $W_{g}$ is the rotor weight and the sub-index $m_{1}$ and $m_{2}$ indicate the upper and lower pad, respectively.

$$
\begin{gathered}
F_{x}=\sum_{1}^{N} F_{x m} \cos \left(\varphi_{j}+\alpha_{j}\right)=0 \\
F_{y}-W_{g}=\sum_{1}^{N} F_{x m} \sin \left(\varphi_{j}+\alpha_{j}\right)-W_{g}=0 \\
F_{y m_{1}}\left(R_{s}+h_{s}\right)=0 \\
F_{y m_{2}}\left(R_{s}+h_{s}\right)=0 \\
F_{x m_{1}}-K_{\text {pivot }, 1} \delta_{m 1}=0 \\
F_{x m_{2}}-K_{\text {pivot }, 2} \delta_{m 2}=0
\end{gathered}
$$

Once Equations 12-17 are satisfied, the static temperature profiles, pad pressure distributions, pad oil film thicknesses, and pad positions can be examined for a given external load and rotational speed. A flowchart of the numerical solution procedure can be seen in Figure 3. The dynamic coefficients are obtained by applying small perturbations to the rotor lateral and angular positions, and velocities as proposed by Lund [3]. Considering the motion of the rotor in the XY plane, the equation of motion can be written with separate terms for the rotor and pad as 


$$
\begin{gathered}
{\left[\begin{array}{cc}
{\left[M_{S}\right]} & 0 \\
0 & {\left[J_{p}\right]}
\end{array}\right]\left\{\begin{array}{l}
\ddot{u} \\
\ddot{\alpha}
\end{array}\right\}+\left[\begin{array}{cc}
{\left[C_{u u}\right]} & {\left[C_{u \alpha}\right]} \\
{\left[C_{\alpha u}\right]} & {\left[C_{\alpha \alpha}\right.}
\end{array}\right]\left\{\begin{array}{c}
\dot{u} \\
\dot{\alpha}
\end{array}\right\}+\left[\begin{array}{cc}
{\left[K_{u u}\right]} & {\left[K_{u \alpha}\right]} \\
{\left[K_{\alpha u}\right]} & {\left[K_{\alpha \alpha}\right.}
\end{array}\right]\left\{\begin{array}{l}
u \\
\alpha
\end{array}\right\}=\left\{\begin{array}{c}
f_{s} \\
0
\end{array}\right\}} \\
u=\left\{\begin{array}{l}
e_{x} \\
e_{y}
\end{array}\right\}, \alpha=\left\{\begin{array}{l}
\alpha_{1} \\
\alpha_{2}
\end{array}\right\}
\end{gathered}
$$

where $M_{s}$ is the rotor mass matrix, $J_{p}$ is the inertia moment matrix, $e_{x}$ and $e_{y}$ are the respective eccentricities in $\mathrm{x}$ and $\mathrm{y}$ directions, $\alpha_{1}$ and $\alpha_{2}$ are the respective angular displacements of the pads 1 and $2, f_{S}$ is the load vector, $K$ and $C$ are the stiffness and damping matrices.

The equation of motion is written in the frequency domain as presented by Equations 20 and 21, where $\gamma$ is a complex eigenvalue. Thus, the reduced coefficients (Eqs. 22 and 23) can be obtained as shown by Dimond [7, 8]

$$
\begin{gathered}
{\left[\left(\gamma C_{u u}+K_{u u}\right)-G_{u u}\right] U=F_{s}-\gamma^{2} M_{s} U} \\
G_{u u}=\left(\gamma C_{u \alpha}+K_{u \alpha}\right) \cdot\left(\gamma^{2} J_{P}+\gamma C_{\alpha \alpha}+K_{\alpha \alpha}\right)^{-1} \cdot\left(\gamma C_{\alpha u}+K_{\alpha u}\right) \\
{[K(\gamma)]_{2 x 2}=\operatorname{real}\left\{\left[\left(\gamma C_{u u}+K_{u u}\right)-G_{u u}\right]_{2 x 2}\right\}} \\
{[C(\gamma)]_{2 x 2}=\text { imaginary }\left\{\frac{1}{\gamma}\left[\left(\gamma C_{u u}+K_{u u}\right)-G_{u u}\right]_{2 x 2}\right\}}
\end{gathered}
$$

\subsubsection{Numerical Method}

The modified Reynolds and energy equations are cast in discrete form using the finite volume method (FVM) and solve numerically. Following Patankar [42], the physical non-uniform domain of the fluid film between journal and pad is transformed into a uniform computational domain.

Figure 3

The pad areas without injection follow the same Reynolds, energy and velocity equations described in Daniel and Cavalca [35] without the injection terms. The injection-modified forms of the equations are restricted to fluid film regions at the orifice locations satisfying

$$
\left(x-x_{0}\right)^{2}+\left(z-z_{0}\right)^{2} \leq \frac{d_{0}^{2}}{4}
$$


The complete system of equations demands an iterative process to solve the pad oil film thicknesses, pressures, velocities, temperatures, and viscosities simultaneously. The method applied to solve the system of equations is the Gauss-Seidel method.

The boundary conditions (BC) applied to the pad oil film identified by the surface numbers in Figure 4 (a). The pad inlet (Surface 1) receives a temperature distribution from the mixing region, as shown in Figure 5 (a). The shaft temperature (Surface 2) is assumed as a prescribed temperature. The pad outlet (Surface 3) and the pad surface (Surface 4) are considered adiabatic. The 3D approach is represented in figure 4 (b). For each position $z_{i}$ in the axial direction, a full finite volume mesh in $x \times y$ directions is completely solved, covering the whole $\mathrm{z}$-direction (bearing length). In addition, Figure 5 (b) is a pictorial representation of the mixture of pad inlet, orifice injection, and pad outlet flows.

The flowchart in Figure 3 contains the sequential procedure used for the solution. First, the temperature distribution and the viscosity field are estimated, and the oil film thickness, pressure distribution and a new temperature field are calculated. In sequence, the convergence is tested for this calculated temperature distribution and the cycle is repeated until the errors between successive iterations become negligible. This iterative solution for the pad film thickness, pressure, and temperatures occur within an outer search algorithm (Newton-Raphson method) to determine the static equilibrium position of the rotor, the angular positions and deformations of pads. After determining the static equilibrium position, the perturbation is applied to obtain the dynamic coefficients of the bearing.

Figure 4

Figure 5

A convergence test was performed to better define the number of volumes used in the discretization, improving the time consumption and the converged results leading to a 
mesh discretization of: $N x=60, N y=60$ and $N z=60$. In this way, the model applies 60 volumes and 61 nodes during the solution for all directions. The convergence criteria assumed for the solution was an absolute error of $10^{-5}$ for pressure, $10^{-3}$ for the absolute global error of temperature and $10^{-2}$ for the absolute error of equilibrium position.

\subsection{Experimental test rig}

The numerical results obtained from the THD model are compared with the experimental results obtained in the test rig developed especially for tilting pad bearings. Details of the manufacturing of components, construction, and instrumentation can be found in the studies of Varela and Santos [39]. The main contribution of the present study is related to temperature measurements in two points on the pad surface. Two thermocouples Type T were placed in the loaded pad (number 2) as shown in Figure 6 (b) and Figure 2 (a). It is possible to see in Figure 6 (b) the position before the injection orifice and after it, where the thermocouples were assembled. Figure 6 (b) also shows the pivot geometry details. Figure 2 (b), $0_{2}$ refers to the position of the displacement sensors $\left(\delta_{y 1}\right.$ and $\left.\delta_{y 2}\right)$ aligned with the shaft on each side of the arm. Moreover, the third displacement sensor $\left(\delta_{y E}\right)$ is located at the extremity of the arm.

The arm, $450 \mathrm{~mm}$ in length, is made of steel with Young's modulus of $2 \times 10^{11} \mathrm{~N} / \mathrm{m}^{2}$. The second moment of area is $1.84 \times 10^{-4} \mathrm{~m}^{4}$ and the stiffness is about $4.04 \times 10^{8} \mathrm{~N} / \mathrm{m}$. The boundary conditions are pinned-free ends with an elastic clamp in the half-length of the arm. Figure 11 (next section 3), shows the order of magnitude of bearing stiffness is $10^{7}$ in the vertical direction, mainly due to the flexibility of the pivot at the pad base. Hence, the arm stiffness is over 4 times higher than the bearing stiffness. Figure 6 
The force and displacement measurements applied in this study were acquired at the extremity of the arm (third sensor, (figure 6 (c), "E")) because the sensor has better accuracy given its position. It is thus necessary to transform the data of the arm extremity $\left(\delta_{y E}\right)$ into the data of the shaft center as

$$
\begin{gathered}
f_{r}=\frac{l_{1}}{l_{2}} f_{\text {static }}+f_{g} \\
\delta_{r}=\frac{l_{1}}{l_{2}}\left(\delta_{e}-\delta_{s}\right), \quad \delta_{f}=\delta_{r}-\delta_{0}
\end{gathered}
$$

where $f_{g}$ the load due to the arm weight, $y_{0}$ the bearing center position and the subindex "static" denotes a measurement made in the arm extremity.

Figure 6 also illustrates that the rotor is effectively constrained in the x-direction, with the rotor motion restricted to the y-direction. This type of arrangement was designed to better represent the decoupling of directions $\mathrm{x}$ and $\mathrm{y}$, characteristic of tilting pad bearings. This restricted motion is inherent in the complete numerical model, wellrepresenting the test-rig setup.

The temperature sensor (Thermocouple Ametek Type $\mathrm{T}$ ) has a sensitivity of $10^{\circ} \mathrm{C} / \mathrm{V}$ with an accuracy of $\pm 0.1^{\circ} \mathrm{C}$, the displacement sensor (Micro-Epsilon eddyNCDT 3010-M s2) has a sensitivity of $0.25 \mathrm{~mm} / \mathrm{V}$ with a resolution of $1 \mu \mathrm{m}$ and the static force sensor (U9B-HBM) has a sensitivity of $1 \mathrm{mV} / \mathrm{V}$ with relative deviation $\pm 1 \%$, being it the main source of uncertainties in the experimental results. It is important to mention that the measurements obtained in the experimental test have good repeatability, presenting background noise (computer) in the order of $0.5 \mathrm{mV}$ and sensor noise in the order of $1.0-1.5 \mathrm{mV}$ when the sensors are connected to DSpace. Thus, low pass filters with a cutoff frequency of $1 \mathrm{KHz}$ were used and the signals acquisition was performed considering the sampling frequency of $2 \mathrm{KHz}$.

\section{RESULTS AND DISCUSSION}

The geometrical dimensions, lubricant properties, and injection characteristics used during the experimental tests and numerical simulations are presented in Table 1. The 
injection orifice is positioned at the pad center, as shown in Figure 6 (b). This figure brings the detail of the pivot geometry

Before testing the bearing subject to rotation, the radial clearance and preload measurements obtained from the displacement sensors were calibrated. For this test, a static load was applied gradually to the rotor load arm in the absence of rotation and, for each load value, the displacements were acquired in the sensors. Figure 7 shows the values of applied forces and the respective displacements of the rotor. The radial clearance $\left(C_{b}\right)$ can be approximated by half of the displacement span at the flat region of the curve, close to null external force, given that the bearing center is located at the midpoint of the curve at the force of $0 \mathrm{~N}$. The responses of the three sensors $\left(\delta_{y 1}, \delta_{y 2}\right.$ and $\delta_{y E}$, represented in Figure 2(b)) are similar and considering that the third sensor $\left(\delta_{y E}\right)$ has better accuracy, its results were chosen as inputs to the numerical simulations: $C_{b}=47.5$ and $y_{0}=246 \mu m$. Additionally, the pivot stiffness can also be evaluated from Figure 7, being the average of the angular coefficients of the linear relation force versus displacement for all proximity sensors: $K_{\text {pivot }_{1,2}}=3.9 \cdot 10^{7} \mathrm{~N} / \mathrm{m}$.

During experimental testing, a rise of the oil reservoir temperature was observed with the rotational speed increase, due to no active control of the reservoir temperature. This effect was considered in the inlet temperature of the TPJB model, namely, replenishment temperature from the oil reservoir. The temperature varies linearly with a rotating speed from $40^{\circ} \mathrm{C}$ at $20 \mathrm{~Hz}$ to $50^{\circ} \mathrm{C}$ at the maximum rotational speed of $70 \mathrm{~Hz}$. In this way, this variation is also used as the inlet temperature for all cases tested, based on the tank oil thermometer.

Table 1

Figure 7 
Preliminary validation of the THD model with radial injection and pad flexibility evaluated the predicted static eccentricity ratio as a function of injection pressure and rotational speed. Figure 8 shows the eccentricity ratio obtained from the THD model compared with the experimental tests for the condition with two levels of injection pressure. All cases of this study considered a load of $500 \mathrm{~N}$ for different rotational speeds. Overall, Figure 8 shows that the proposed THD model predicts static eccentricity in agreement with the experimental results, with notable accuracy at an injection of 10 bar.

Figure 8

Temperature predictions and measurements (points 1 and 2) are compared for the TPJB without injection and with an injection pressure of 10 bar in Figures 9 (a) and 9 (b), respectively, as a function of rotational speed. With an injection pressure of $10 \mathrm{bar}$, lower pad temperatures were both observed and predicted due to the flow of cold oil replacement in the middle of the pads. At low rotational speeds, the THD model predicted pad temperatures compare well with the experimental temperatures but show higher deviation at higher rotational speeds. Figure 9 (c) shows the results for $700 \mathrm{~N}$ with 10 bar, also achieving higher temperatures due to the increase in the load when compared with the same condition at $500 \mathrm{~N}$ and $10 \mathrm{bar}$. It is important to point out the nomenclature applied in the graph's legend. For the thermocouple installed before the pad center orifice (injection) the name of the data received "Before injection" and for the thermocouple installed after the injection orifice the data name received "After injection". The injection system was full time turned on (continuous mode) during the tests. The main target of this system is to supply lubricant to cool down the oil film temperature. 
Knowing that each rotational speed demanded about two hours to achieve the equilibrium condition, the temperature increasing during the experimental procedure along with the heating of the complete system (arm, shaft and oil deposit) can be indicated as the main discrepancy between the model results and the experimental data (Figure 9). This point also intensifies the discrepancy between the data with the highest rotation speed, which was the last acquisition data. With a temperature controller of the replacement oil to keep the inlet temperatures constant for the entire rotation range, the agreement between experiment and numerical simulation would be certainly improved. Figure 9

After the comparison of numerical and experimental results of the eccentricity ratio and the temperature for the TPJB, the dynamic coefficients of the bearing are investigated. Firstly, the stiffness coefficient obtained in the proposed model is compared with results available in the literature, as presented by Andritsos and Dimarogonas [43]. The comparison of the results is presented in Figure 10, reminding the bearing configuration of this work is "Load on Pad" with a preload of 0.76 . As can be observed, the numerical results are positioned between 0.7 and 0.8 preloads results presented by Andritsos and Dimarogonas [43], corroborating with the developed model.

Figure 10

A subsequent analysis was performed to verify the influence of the effects of the injection pressure and pivot flexibility on the stiffness and damping coefficients of the TPJB. A bearing load of $500 \mathrm{~N}$ was considered for four cases with permutations in injection pressure, 0 vs. 10 bar, and rigid vs. flexible bearing pads. Table 2 contains the characteristics of pivot flexibility and injection pressure for the four cases evaluated and Figure 11 (a)-(b) shows the results for the direct stiffness and damping coefficients in the y-direction. It is worth noting the pivot flexibility of considerable influence on the bearing dynamic coefficients since its effect is more relevant when compared with the injection effect. It is also stated the low variance of the stiffness coefficients with 
injection, compared to damping, that presented a higher influence of this variation. In this way, it is remarkable the influence of the pivot flexibility on the bearing coefficients (for both stiffness and damping), when compared to the effect of the direct injection flow. Similar behavior is also observed when considering a pressure injection of $30 \mathrm{bar}$, since the flexibility of the pivot maintains a predominant influence on the dynamic coefficients of the bearing.

\section{Table 2}

Figure 11

Since the test rig has no load application in the x-direction and all measurements are obtained in the y-direction, the model simulates the same condition. In this context, the reduction of coefficients is noticeable when comparing the system with and without pivot flexibility, due to the increase in oil film thickness and the consequent reduction of film pressures and temperatures. The pressure injection also decreases the coefficients.

Regarding the oil flow between shaft and pad, the laminar condition is ensured for the different injection pressures of 0bar, 10bar and 30bar, since the Reynolds number is, respectively, 20.20, 24.14 and 28.62, considering the maximum shaft rotational speed of 76Hz. Laminar condition is also found for the flow inside the injection tube orifice, being the Reynolds numbers equal to 0.14 and 0.17 for the injection pressures of 10 bar and 30 bar, respectively.

Figure 12 shows the pressure distribution and Figure 13 shows the temperature distributions for all cases presented in Table 2 with a rotational speed of $\omega=55 \mathrm{~Hz}$. The results indicate a decrease in pressure values when considering the pivot flexibility, causing an increase in oil film thickness and a consequent decrease in temperature. For the cases with injection, pressures at the orifice location remain fixed (imposed injection 
pressure) as shown in Figure 12. The temperature distribution in Figure 13 shows the difference between the upper and lower pads. As the lower pad is the highest loaded, the oil film thickness is thinner and, consequently, the temperature increase is more significant than in the upper pad.

\section{Figure 12}

\section{Figure 13}

Considering the cases with injection (cases 2 and 4), Figure 14 shows the isotherm surfaces considering the 3D domain. When both injection and pivot flexibility are considered, corresponding to Figure 14 (b), the maximum temperatures (approximately $52^{\circ} \mathrm{C}$ ) are reduced from the peak TPJB temperatures (approximately $56^{\circ} \mathrm{C}$ ) shown in Figure 14 (a) considering injection only.

Figure 14

\section{CONCLUSIONS}

In this work, a numerical model of the TPJB considering lubricant injection in the middle of the pad, pad pivot flexibility, and temperature variation across the lubricant film were developed. Considering the validation of the model, experimental tests were made in a dedicated test rig and temperatures were compared with the simulated results.

The eccentricity ratios obtained by applying the proposed model are compared closely with the experimental results, with the closest agreement at an injection pressure of 10 bar.

When comparing temperature distribution, the consideration of the pivot flexibility causes the oil film cooling and the pressure decreasing due to the thicker oil film. 
The predicted values of damping and stiffness coefficients were physically consistent with the test-rig setup in that non-zero coefficients were obtained only in the y-direction.

Considering that the limit speed tested achieves about $12 \mathrm{~m} / \mathrm{s}$ and that the main focus of this work was to investigate the temperature behavior with the oil injection in the pad center along with the impact on the eccentricity, further analysis can be proposed to verify the turbulent flow and inlet mixtures considering higher rotor surface speeds on the test.

Finally, the injection behavior found by the numerical simulations, evidenced by Figures 12 and 13, demonstrated a coherent behavior when compared with the case without injection and with the presence of pivot flexibility. For the case with pivot flexibility, when considering the injection pressure, a higher injection profile was found due to the lower pressure acting on the surface of each pad; also, the opposite is noted for the case with injection and without pivot flexibility.

The main limitation during the development of the present work was to control the oil supply replacement temperature to accurately enter this information in the numerical model. This difference in the inlet temperature on the model can generate some discrepancies in the temperature results, mainly for high rotational speeds, due to the increase in a temperature difference (longest test time).

Another observation during the experimental procedure was that for very high rotation speed and injection pressure in the pad center the oil starts to foam and smoking, which indicates strong changes in the physics of the problem. Besides the limitations, it was possible to compare the experimental and numerical model data, considering the y-direction of load application and verify the impact of the injection 
system and pivot flexibility consideration on the bearing dynamic coefficients and pressure and temperature at the nominal operating condition.

\section{ACKNOWLEDGMENTS}

The authors would like to thank the National Council for Scientific and Technological

Development (CNPq grant \#307941/2019-1), the São Paulo Research Foundation (Fapesp) for Grants \#2015/20363-6 and \#2017/18629-3 and Petrobras Brazil for the financial support to this research. The authors also thank Espaço da Escrita - PróReitoria de Pesquisa - UNICAMP - for the language services provided.

\section{REFERENCES}

[1] GLIENICKE, J., Stabilitatsprobleme bei Lagerung schnellaufender Wellen - Berechnung, Konstruktion und Verhalten von Mehrflchen und Kippsegmentlagern, Technische Akademie Wuppertal, Germany, 1987.

[2] FLACK, R. D., ZUCK, C. J., Experiments on the Stability of Two Flexible Rotor in Tilting Pad Journal Bearing, Tribology Trans., vol. 31, no. 2, pp. 251_257, 1988.

[3] LUND, J., Spring and Damping for the Tilting Pad Journal Bearings, ASLE Trans., vol. 7, no. 4, pp. 342 352, 1964.

[4] NICHOLAS, J., Lund's Tilting Pad Journal Bearing Pad Assembly Method, ASME Journal of Vibrations and Acoustics, vol. 125, pp. 448_454, October 2003.

[5] ALlAIRE, P., PARSELL, J., BARRET, L., A Pad Perturbation Method for the Dynamic Coefficients of Tilting-Pad Journal Bearings, Wear, vol. 72, pp. 29_44, 1981 .

[6] DIMOND, T., YOUNAN, A., ALlAIRE, P., Comparison of Tilting-Pad Journal Bearing Dynamic Full Coefficient and Reduced Order Models Using Modal Analysis, ASME Journal of Vibration and Acoustics, vol. 132, October 2010. 
[7] DIMOND, T., SHETH, P., ALLAIRE, P., HE, M., Identification methods and test results for tilting-pad and fixed geometry journal bearing dynamic coefficients - A review, Shock and Vibration, vol. 16, pp. 13_43, 2009.

[8] BROCKWELL, K., KLEINBUB, D., DMOCHOWSKI, W., Measurement and Calculation of the Dynamic Operating Characteristics of the Five Shoe Tilting-Pad Journal Bearing, STLE Tribology Transactions, vol. 33, no. 4, pp. 481_492, 1989.

[9] HA. H., YANG, S., Excitation Frequency Effects on the Stiffness and Damping Coefficients of a Five Pad Tilting Pad Journal Bearing, ASME Journal of Tribology, vol. 121, no. 3, pp. 517_522, 1999.

[10] DMOCHOWSKI, W., Dynamic Properties of Tilting-Pad Journal Bearings: Experimental and Theoretical Investigation of Frequency Effects due to Pivot Flexibility, ASME Journal of Engineering for Gas Turbines and Power, vol. 129, pp. 865_869, July 2007.

[11] CHILDS, D., CARTER, C., Rotordynamics Characteristies of a Five Pad, Rocker-Pivot, Tilting Pad Bearing in a Load-on-Pad Configuration; Comparisons to Predictions and Load-Between-Pad Results, ASME Journal of Engineering for Gas Turbines and Power, vol. 133, August 2011.

[12] ETTLES, C., The Analysis and Performance of Pivoted Pad Journal Bearings considering Thermal and Elastic Effects, J. Lubr. Tech., ASME Trans., vol. 102, no. 2, pp. 182_194, 1980.

[13] BROCKWELL, K., DMOCHOWSKI, W., Thermal Effects in the Tilting Pad Journal Bearing, J.Phys.D: Appl.Phys, vol. 25, pp. 384_392, 1992.

[14] LUND, J., The Influence of Pad Flexibility on the Dynamic Coefficients of a Tilting Pad Journal Bearing, ASME Journal of Tribology, vol. 109, pp. 65_70, 1987.

[15] FILLON, M., BLIGOUD, J. C., FRÊNE, J., Experimental Study of Tilting-Pad Journal Bearings Comparison with Theoretical Thermoelastohydrodynamic Results, ASME Journal of Tribology, vol. 114, pp. 579_588, 1992.

[16] EARLES, L., PALAZZOLO, A., ARMENTROUT, R., A Finite Element Approach to Pad Flexibility Effects in Tilting Pad Journal Bearings: Part I Single Pad Analysis, ASME Journal of Tribology, vol. 112, pp. 169_177, 1990. 
[17] EARLES, L., PALAZZOLO, A., ARMENTROUT, R., A Finite Element Approach to Pad Flexibility Effects in Tilting Pad Journal Bearings: Part II Assembled Bearing and System Analysis, ASME Journal of Tribology, vol. 112, pp. 178_182, 1990.

[18] KIM, J., PALAZZOLO, A., GADANGI, R., TEHD Analysis for Tilting Pad Journal Bearings using Upwind Finite Element Method, Tribology Transactions, vol. 37, no. 4, pp. 771_783, 1994.

[19] RAUD, X., FILLON, M., HELENE, M., Numerical modelling of hydrostatic lift pockets in hydrodynamic journal bearings-Application to low speed working conditions of highly loaded tilting pad journal bearings. Mechanics \& Industry, 2013, 14(5), 327-334.

[20] HAGEMANN, T., PFEIFFER, P., SCHWARZE, H. Measured and Predicted Operating Characteristics of a Tilting-Pad Journal Bearing with Jacking-Oil Device at Hydrostatic, Hybrid, and Hydrodynamic Operation. Lubricants 2018, 6, 81.

[21] BUCHHORN, N., KUKLA, S., BENDER, B., NEUMANN, M., Tilting-Pad Journal Bearing in Hybrid Operation: A Numerical and Experimental Investigation, 2018, Volume 7B: Structures and Dynamics. doi:10.1115/gt2018-75256.

[22] YANG, Q. et al., "Dynamic properties of LEG tilting pad fluid film bearing," 2015 International Conference on Fluid Power and Mechatronics (FPM), Harbin, 2015, pp. 1006-1010, doi: 10.1109/FPM.2015.7337262.

[23] BROCKWELL, K., DMOCHOWSKI, W. DeCAMILLO, S., "Performance Evaluation of the LEG Tilting Pad Journal Bearing", I Mech E Seminar Plain Bearings-Energy Efficiency and Design, 1992, MEP, London, England, pp. 5158.

[24] ULBRICH, H., ALTHAUS, J., Actuator Design for Rotor Control, ASME Design Technical Conference: Proceedings of the 12th Biennial Conference on Mechanical Vibration and Noise, pp. 17_22, 1989. 
[25] SANTOS, I. F., Design and Evaluation of Two Types of Active Tilting Pad Journal Bearings, in The Active Control of Vibration (C.R. Burrows and P.S. Keogh, eds.), pp. 79_87, London, England: Mechanical Engineering Publications Limited, 1994.

[26] SANTOS, I. F., RUSSO, F., Tilting-Pad Journal Bearings with Electronic Radial Oil Injection, Journal of Tribology, ASME Trans., vol. 120, no. 3, pp. 583_594, 1998.

[27] SANTOS, I. F., NICOLETTI, R., THD Analysis in Tilting-Pad Journal Bearings using Multiple Orifice Hybrid Lubrication, Journal of Tribology, ASME Trans., vol. 121, pp. 892_900, 1999.

[28] HAUGAARD, A. M., SANTOS, I. F., Stability of Multi Orfice Active Tilting-Pad Journal Bearings, Tribology International, vol. 43, no. 9, pp. 1742_1750, 2010.

[29] SANTOS, I. F., Theoretical and Experimental Identification on the Stiffness and Damping Coefficients of Active-Tilting Pad Journal Bearings, in Identification in Engineering Systems (M. Friswell and J. Mottershead, eds.), pp.325_334, Swansea, Great Britain: The Cromwell Press Ltd., 1996.

[30] CHANG, Q., YANG, P., MENG, Y., WEN, S., Thermoelastohydrodynamic analysis of the static performance of tilting-pad journal bearings with the Newton-Raphson method. Tribology International, 2002, 35(4), 225234. doi:10.1016/s0301-679x(01)00108-6

[31] NILSSON, L.R.K., The influence of bearing flexibility on the Dynamic Performance of Radial Oil Film Bearings". Proceedings $5^{\text {th }}$ Leads-Lyon Symposium, Mech. Engrg. Publications Ltd., pp311-319 (1978).

[32] SAN ANDRES, L., and LI, Y., 2015, "On the Effect of Pad Flexibility on the Force Performance of Tilting Pad Journal Bearings: A Guide to Benchmarking a Predictive Model,” ASME Paper No. GT2015-42776.

[33] GAINES, J., 2014, "Examining the Impact of Pad Flexibility on the Rotordynamic Coefficients of Rocker-Pivot-Pad Tilting-Pad Journal Bearings," M.S. thesis, Texas A\&M University, College Station, TX.

[34] SUH, J., CHOI, Y-S., Pivot design and angular misalignment effects on tilting pad journal bearing characteristics: Four pads for load on pad configuration, Tribology International, Vol.102, 2016, PP. 580-599. 
[35] DANIEL, G. B., CAVALCA, K. L., Evaluation of the Thermal Effects in Tilting Pad Bearing, International Journal of Rotating Machinery, vol. 2013, Article ID 725268, 17 pages, 2013.

[36] BIZARRE, L., ANDERSEN, T. B., DANIEL, G. B., SANTOS, I. F., CAVALCA, K. L., A 3D Approach for THD Lubrication in Tilting Pad Journal Bearing - Theory and Experiment, Tribology Transactions, 63:1, 120$132,2020$.

[37] DOWSON, D., A generalized Reynolds equation for fluid-film lubrication, International Journal of Mechanical Sciences, Volume 4, Issue 2, 1962, Pages 159-170.

[38] CAMERON, A., Heat Transfer in Journal Bearings: A Preliminary, Investigation, Proceedings of the 1951 general Discussion on Heat Transfer, Inst. Mech. Engr. (1951) pp. 194-197.

[39] VARELA, A., SANTOS, F. I., Tilting-Pad Journal Bearings with Active Lubrication Applied as Calibrated Shakers: Theory and Experiment. ASME. J. Vib. Acoust. 2014; 136(6):061010-061010-11. doi:10.1115/1.4028452.

[40] WALTHER, C., Erdöl und Teer. 7 (1931) 382

[41] WALTHER, C., Maschinenbau. 10 (1931) 670.

[42] PATANKAR, S. V., Numerical Heat Transfer and Fluid Flow, Taylor \& Francis. 1980.

[43] ANDRITSOS, F. E., DIMAROGONAS, A. D., Nonlinear Pad Functions for Static Analysis of Tilting Pad Bearings, J. of Lubrication Tech. Jan 1980, 102(1): 28-33, https://doi.org/10.1115/1.3251433. 


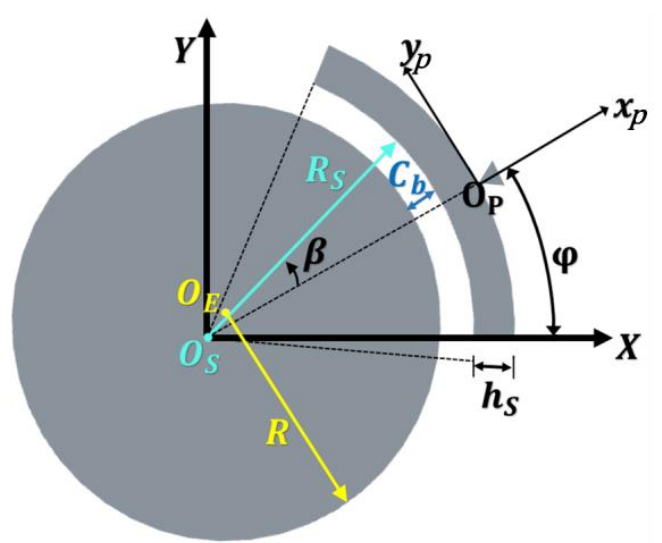

(a)

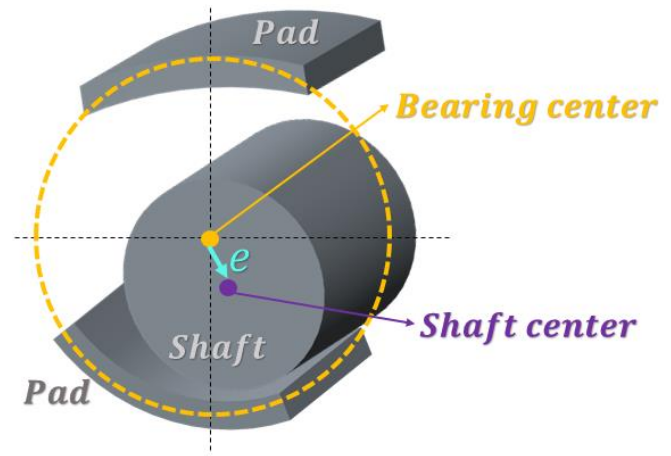

(c)

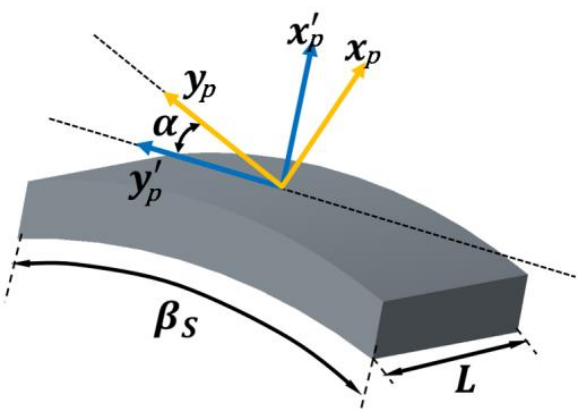

(b)

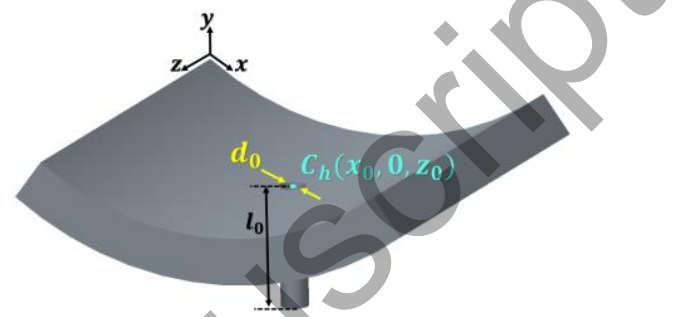

(d)

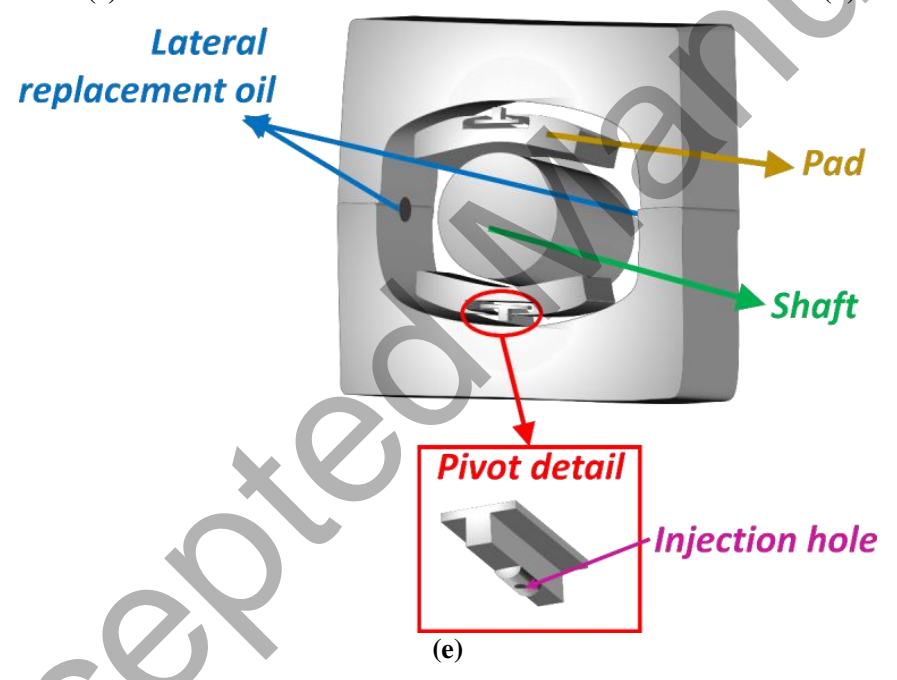

Figure 1. (a) and (b) Representation of TPJB geometry and reference coordinate systems, (c) Schematic of the shaft eccentricity, (d) Dimensions of the orifice for direct, radial oil injection and (e) Schematic representation of the pivots, pads and shaft inside the mancal housing along with the pad injection hole and the lateral holes for oil replacement. 

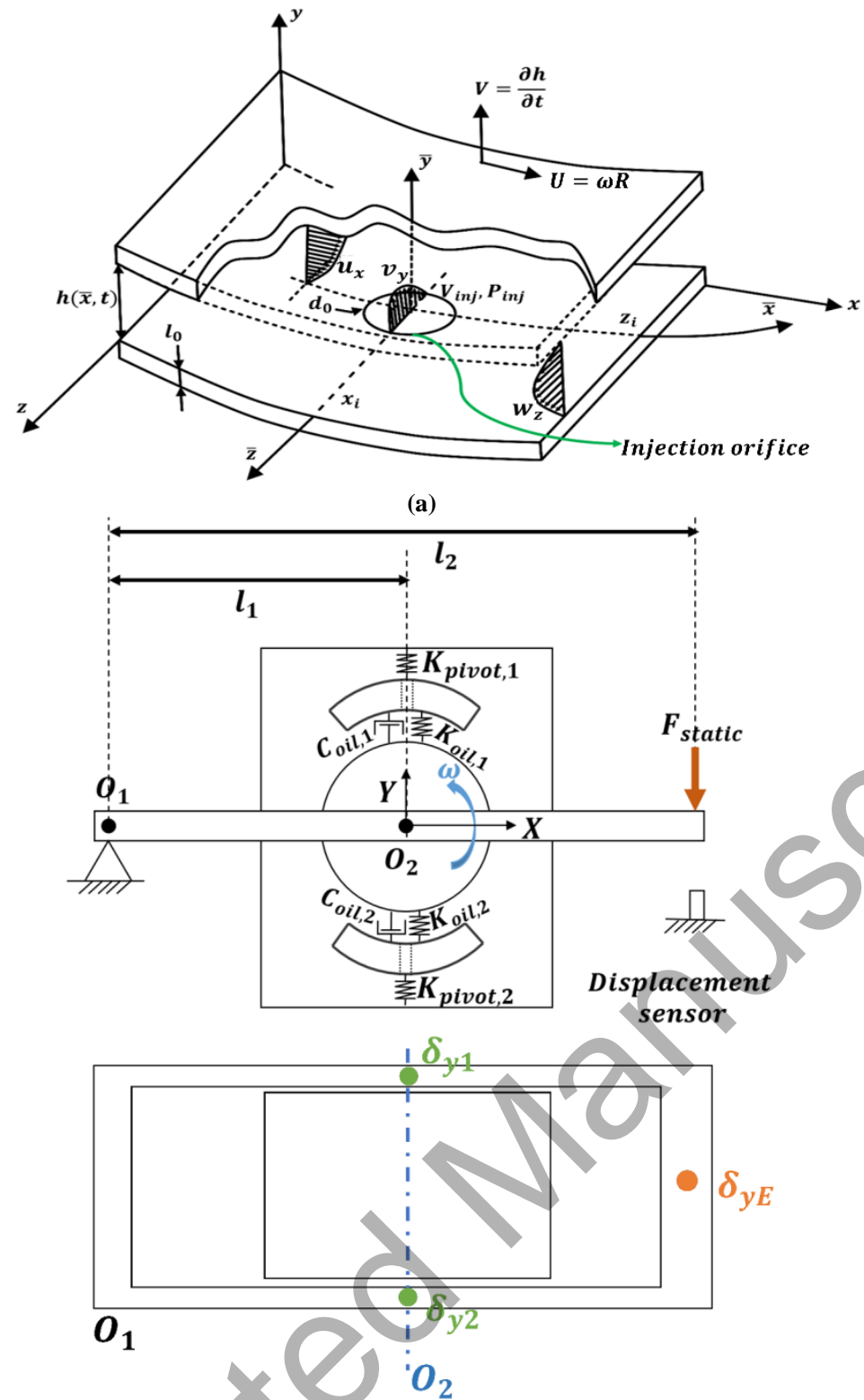

(b)

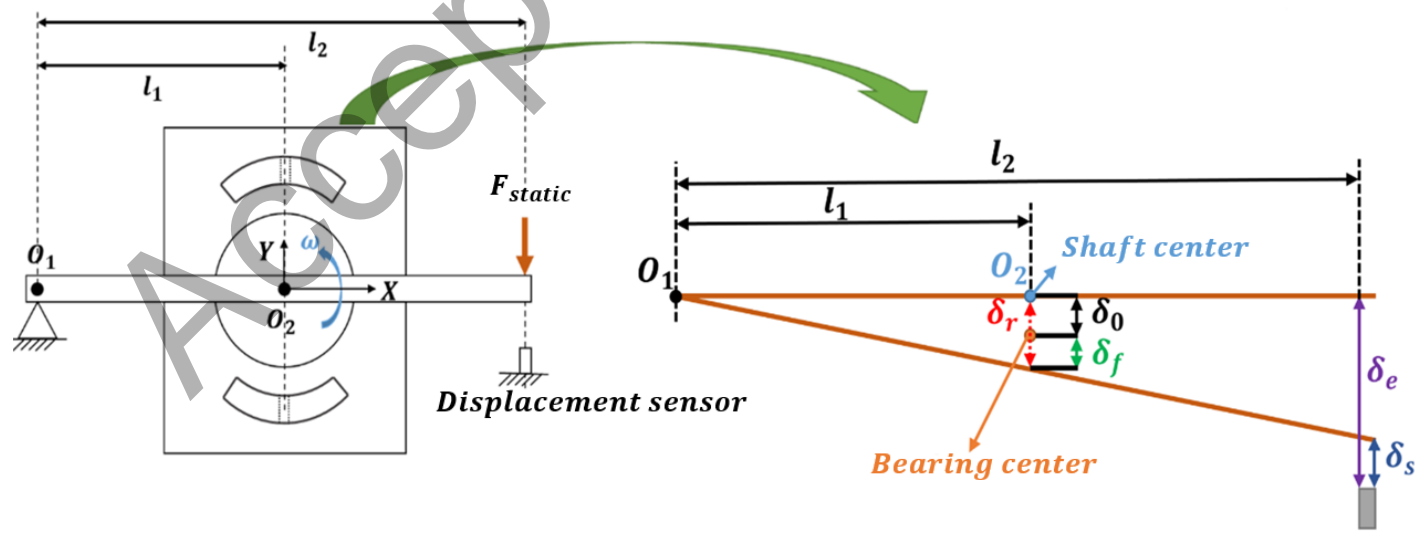

(c)

Figure 2. (a) Schematic of the velocity profiles considering radial injection in the middle of the pad. (b) Mechanical model of the TPJB test rig, (c) Schematic of displacements along loading beam. 


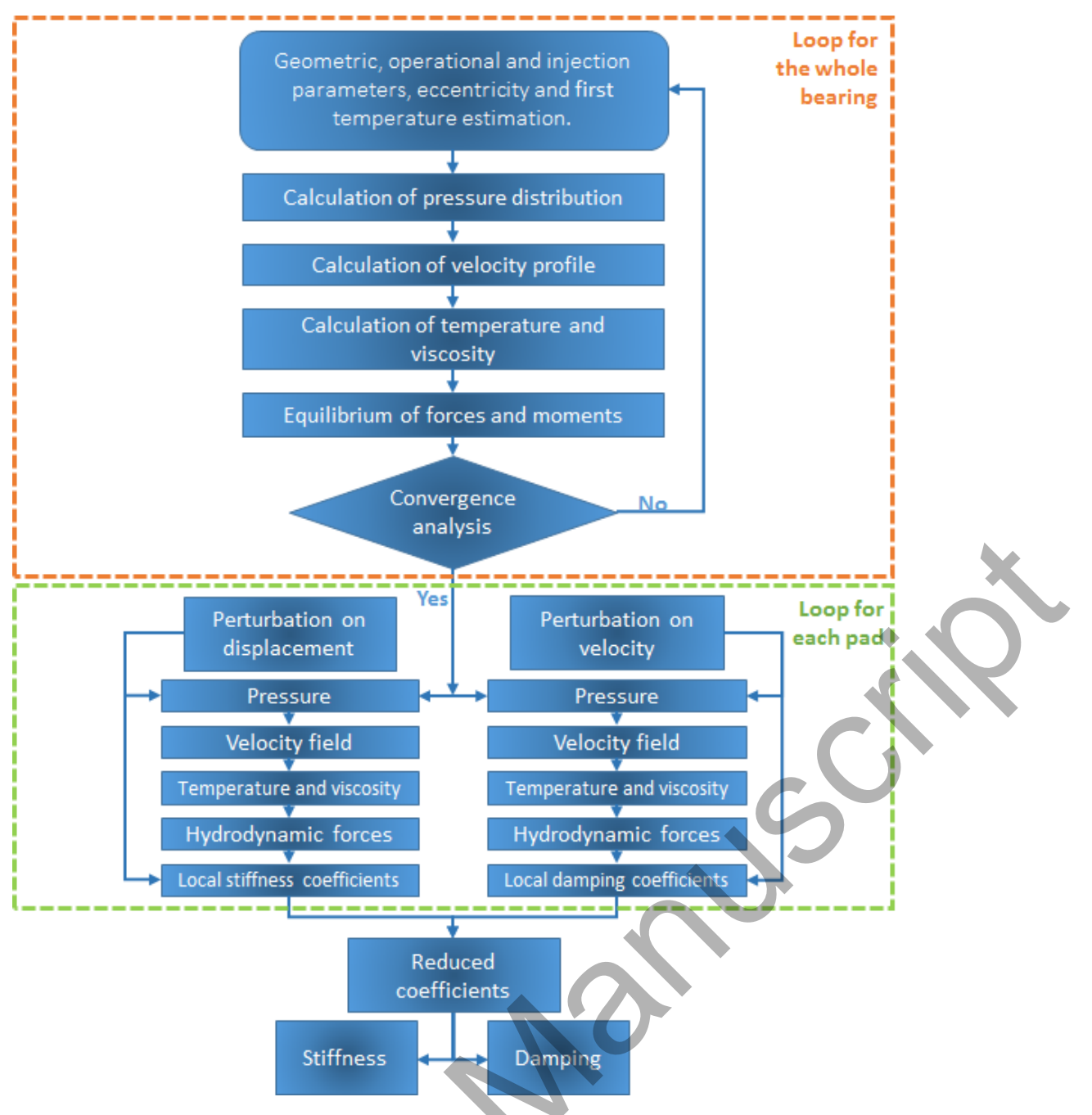

Figure 3. Numerical method flowchart

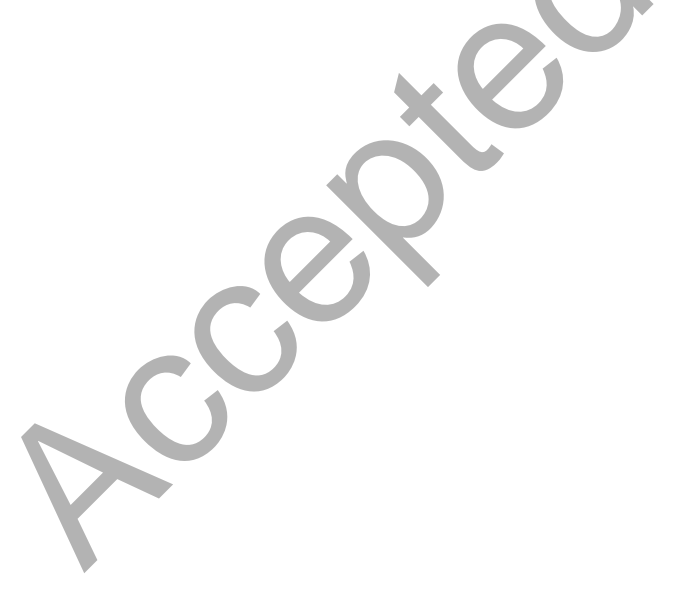




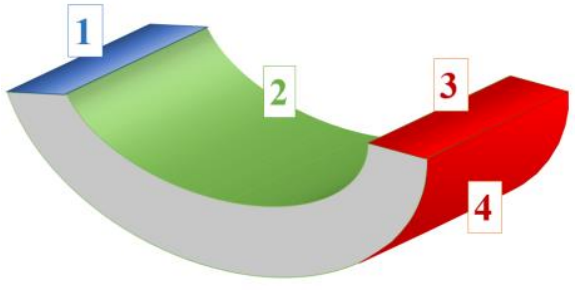

(a)

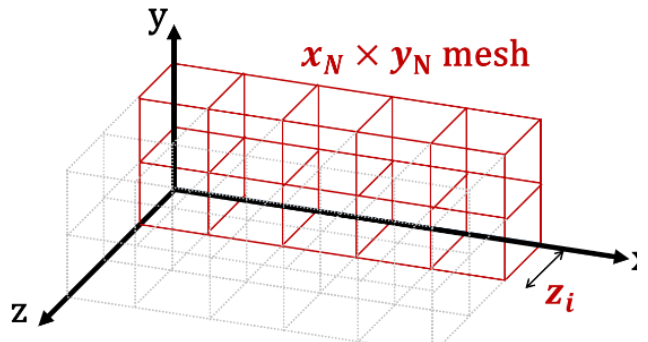

(b)

Figure 4. (a) Boundary condition labels for each border of the fluid film between shaft and pads and (b) Scheme of the energy equation integration, considering a $x_{N} \times y_{N}$ mesh for each $z_{i}$ volume. 


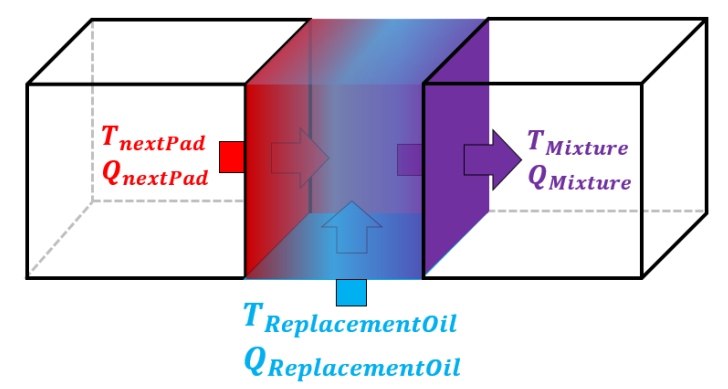

(a)

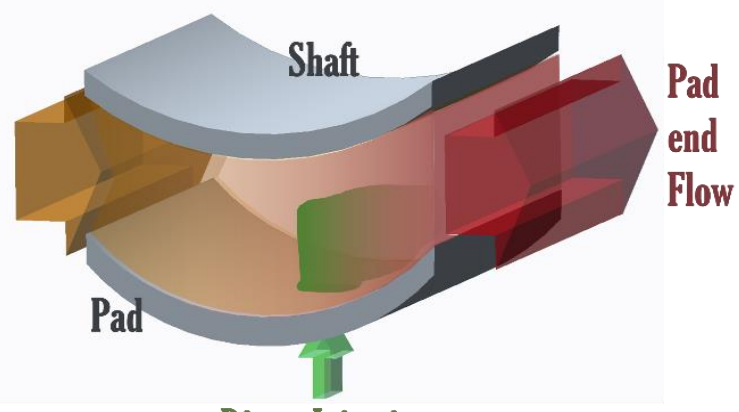

Direct Injection

Flow

(b)

Figure 5. (a) Mixture region on the inlet/outlet of each pad and (b) Schematic of direct injection on the pad middle. 

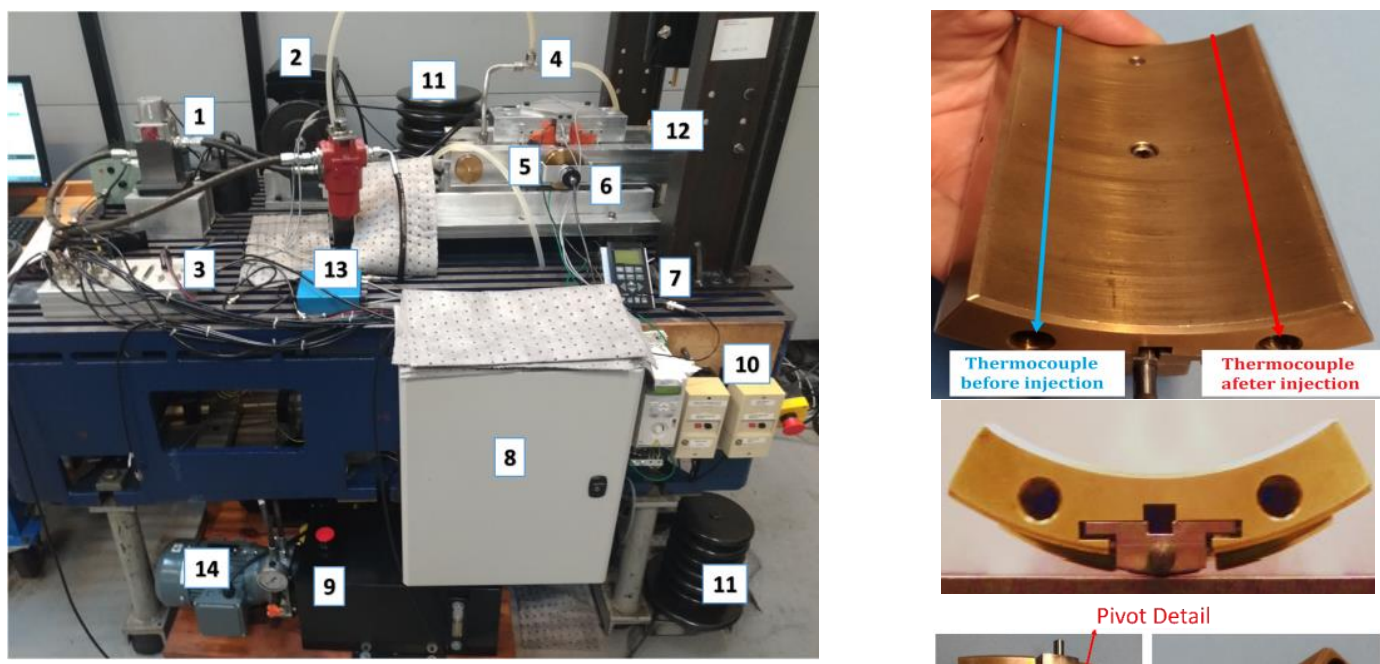

Pivot Detail

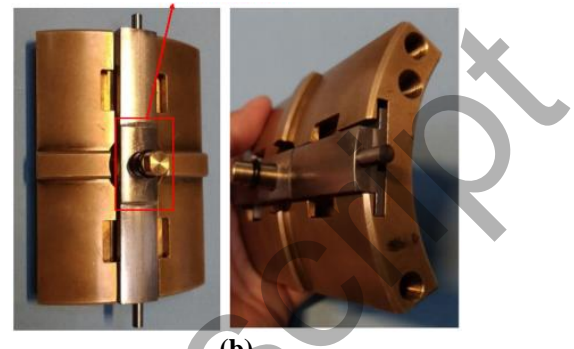

(a)

(b)

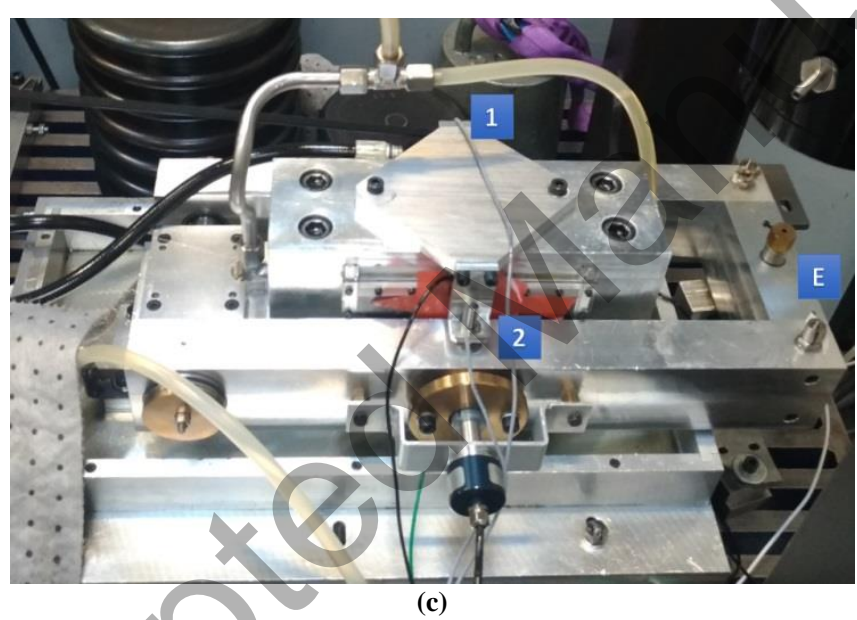

Figure 6. (a) TPJB test rig applied in the experimental tests: (1) Servo valve, (2) Electric motor, (3) Acquisition dSPACE, (4) Distribution pipe of the low-pressure oil line, (5) Arm, (6) Encoder to measure shaft rotation, (7) Display to control motor rotation, (8) Connection center of cables and sensors, (9) Oil tank, (10) On/Off button of pressurizing systems for oil and cooling oil (low pressure), (11) Weights for static load, (12) Displacement and load sensor, (13) Signal conditioner, (14) Pump. (b) Thermocouples positions on the pad and pivot point detail. (c) Details of the displacement sensors position: $1\left(\delta_{y 1}\right), 2\left(\delta_{y 2}\right)$ and $\mathrm{E}\left(\delta_{y_{E}}\right)$, on arm extremity). 


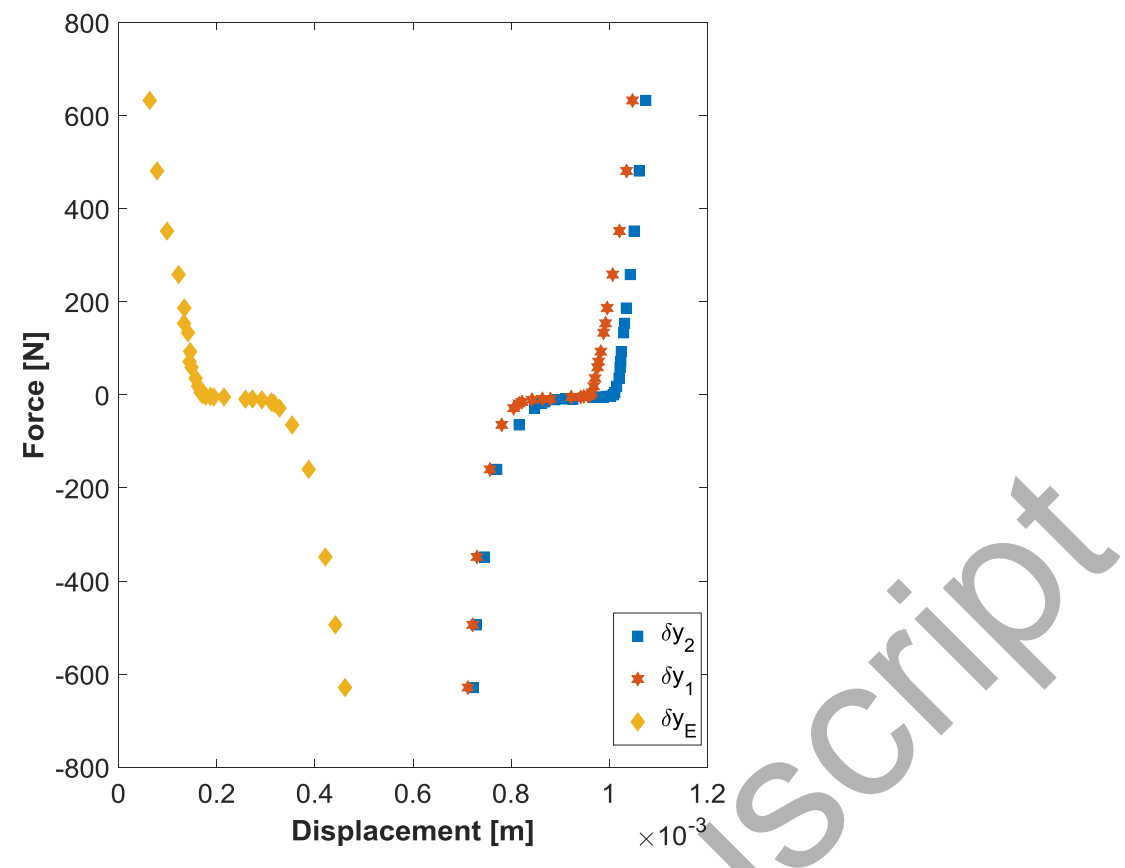

Figure 7. Experimental static force vs. displacement obtained during pre-load calibration procedure at zero rotational speed. 


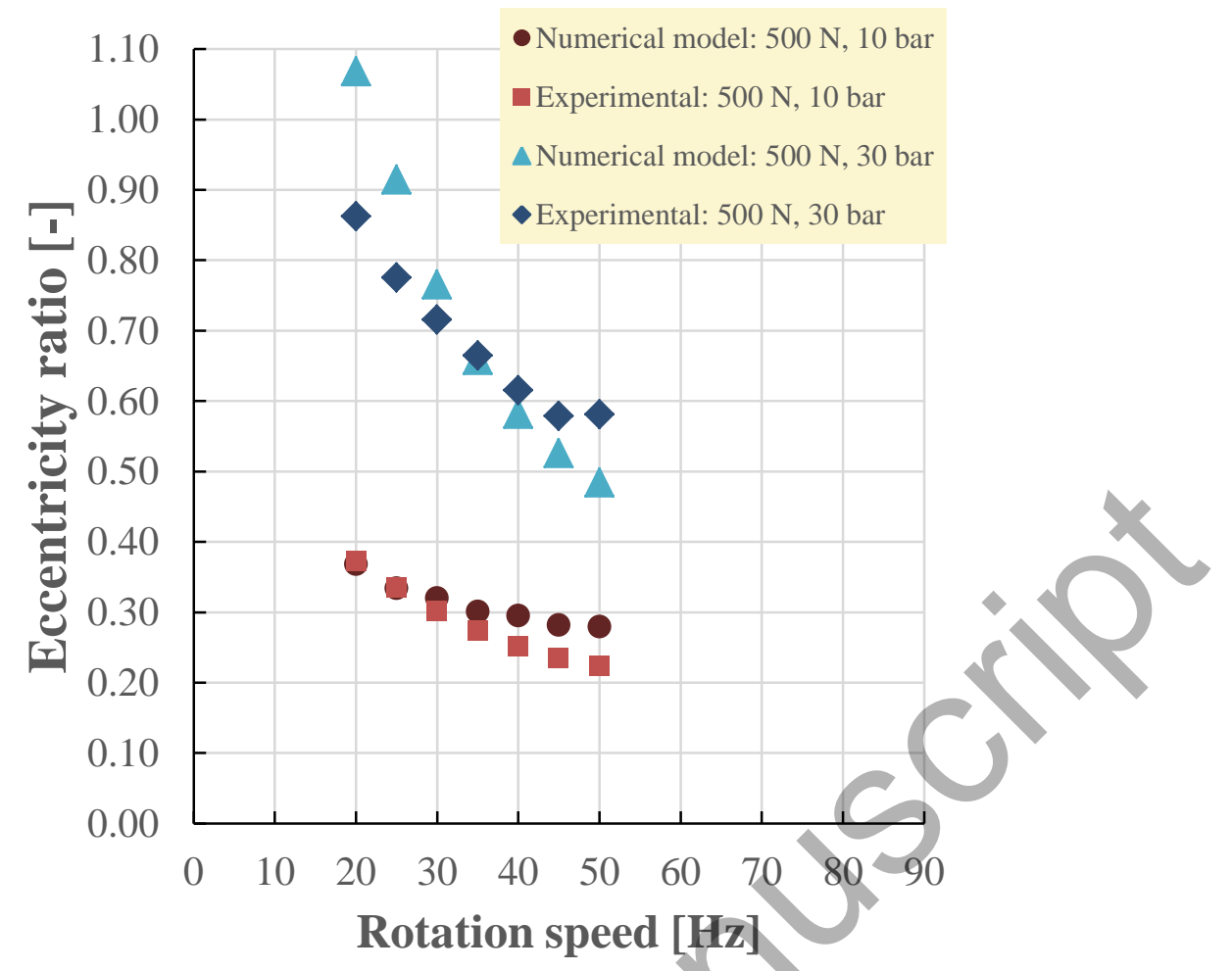

Figure 8. Comparison of numerical and experimental eccentricity ratios for different injection conditions (10bar and 30bar). 


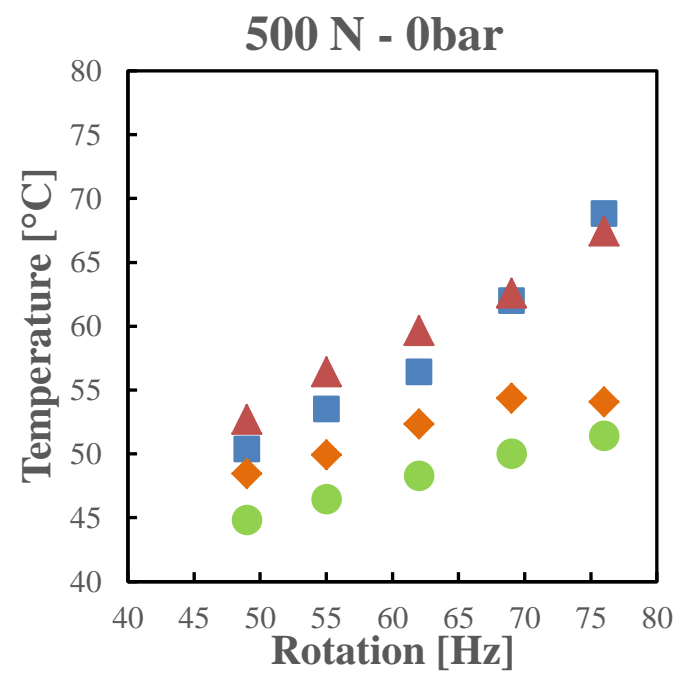

(a)

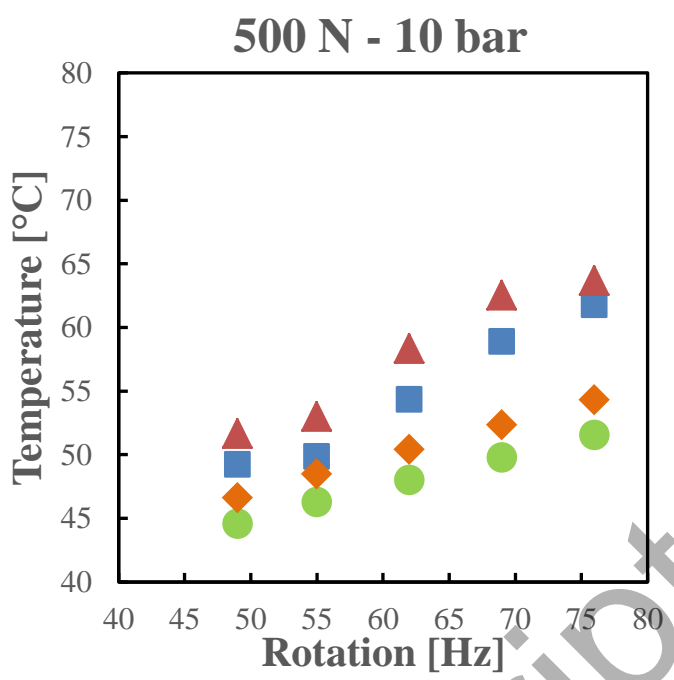

(b)

- Experimental Temp. before injection

$\triangle$ Experimental Temp. after injection

- Model Temp. before injection

- Model Temp. after injection

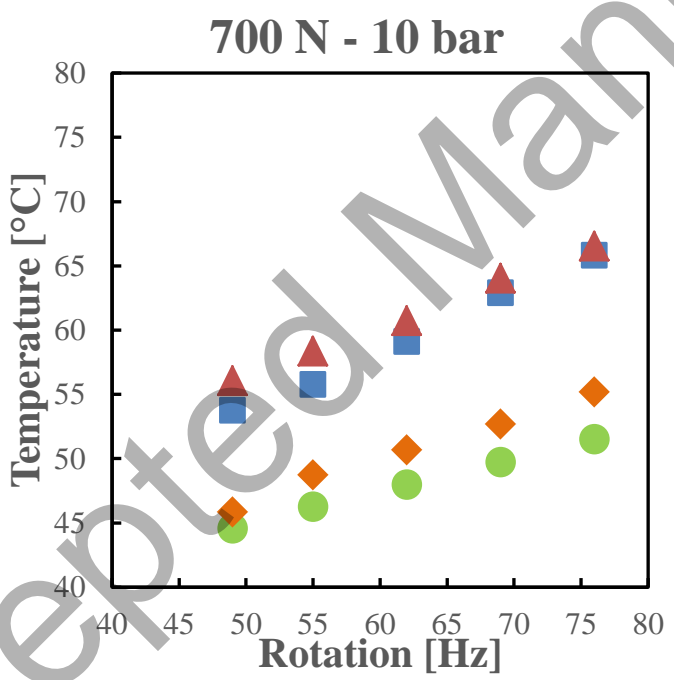

(c)

Figure 9. Comparison of numerical and experimental results of the temperature on the pad for cases: (a) without injection in $500 \mathrm{~N}$, (b) with 10 bar of injection and $500 \mathrm{~N}$, (c) with 10 bar of injection and $700 \mathrm{~N}$. 


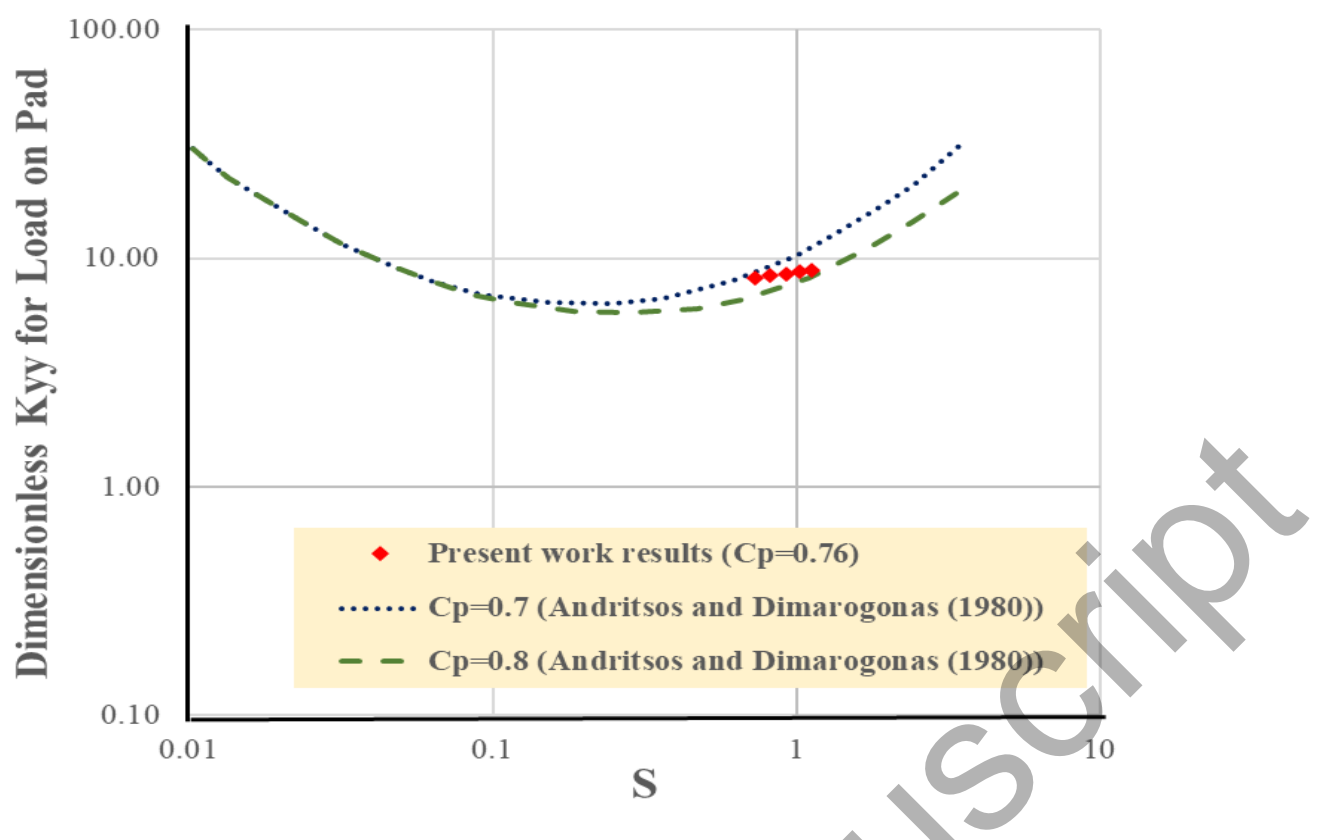

Figure 10. Comparison between stiffness coefficients obtained in this work and available in the literature (Andritsos and Dimarogonas [43]). 


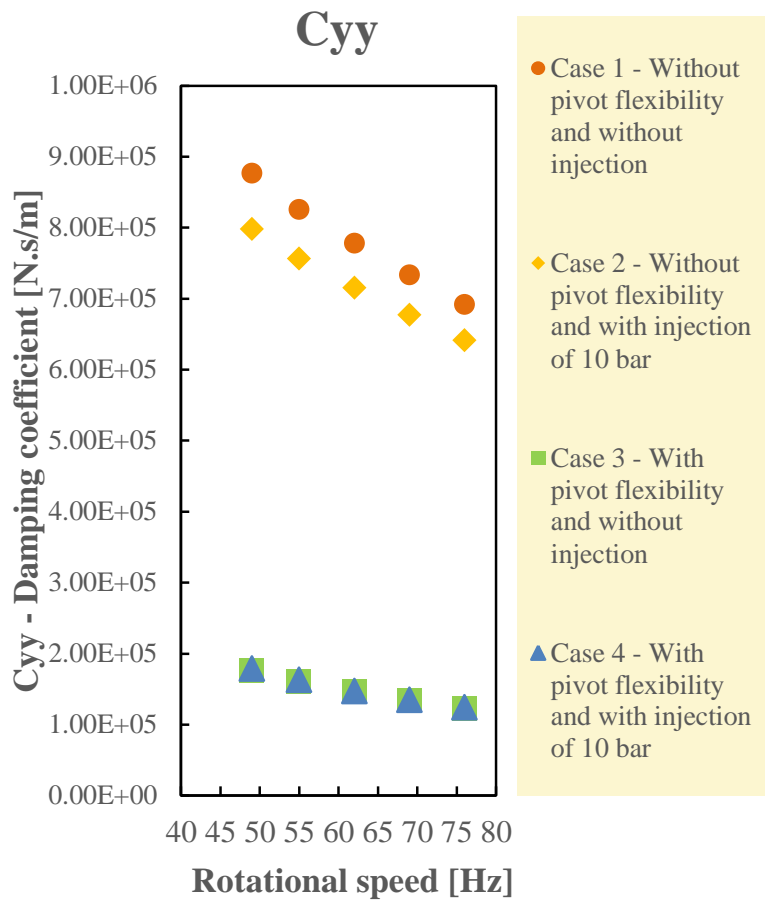

(a)

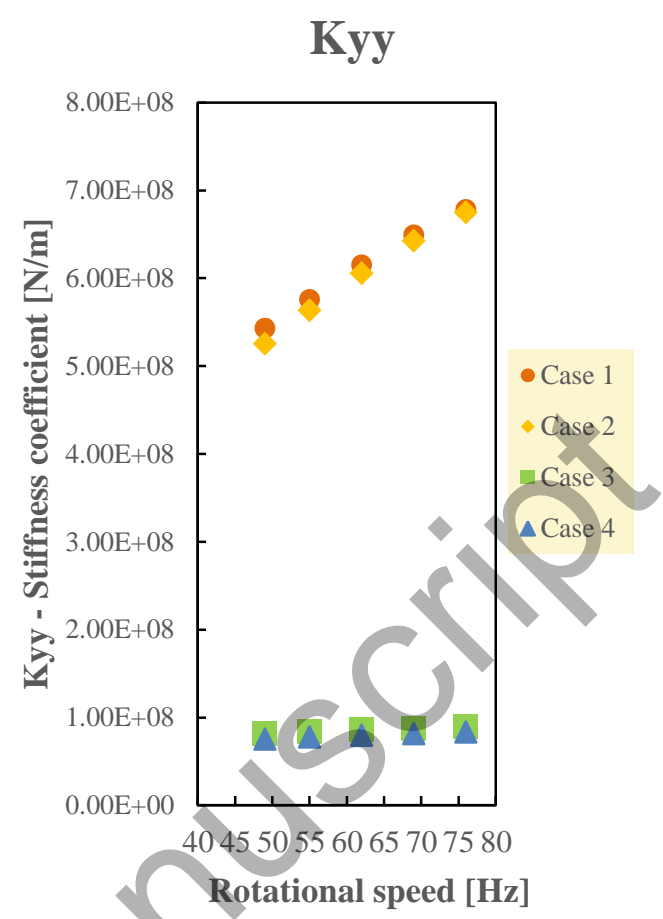

(b)

Figure 11. (a) Numerical results of damping coefficients; (b) Numerical results of stiffness coefficients. 


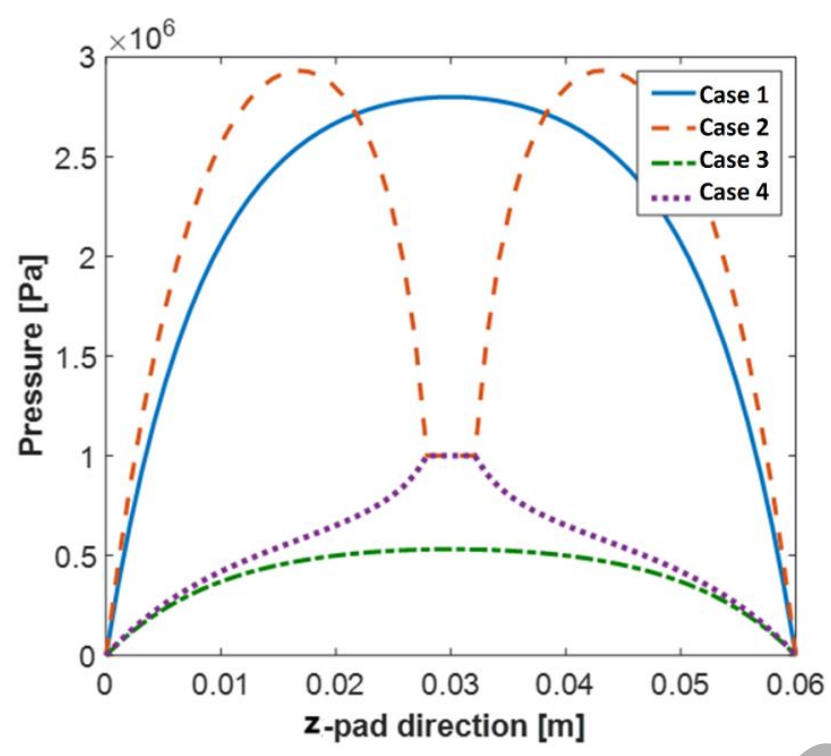

Figure 12. Results of pressure profile on the lower pad for the four cases tested (zdirection). 


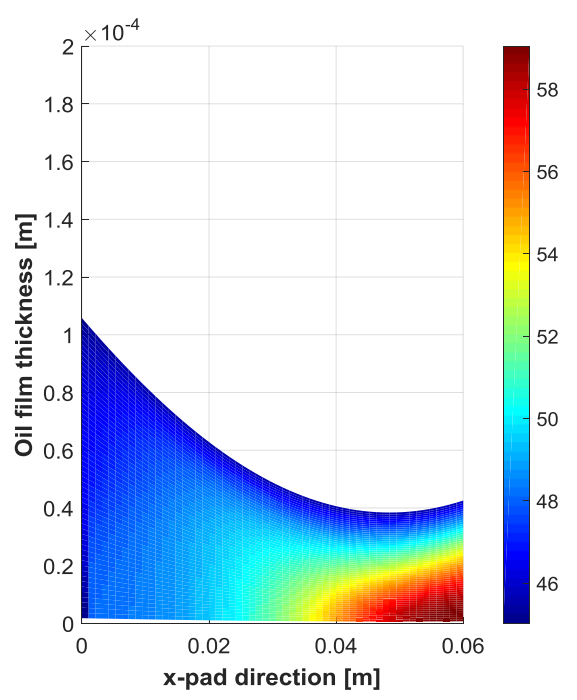

(a)

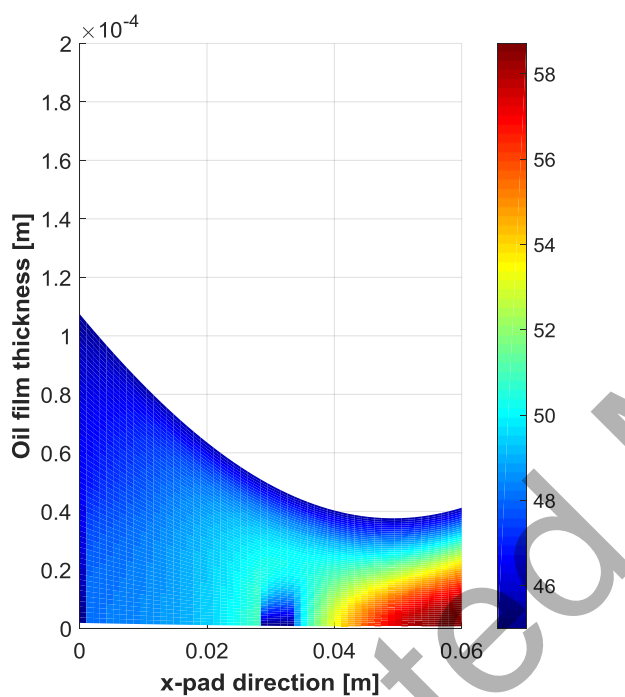

(c)

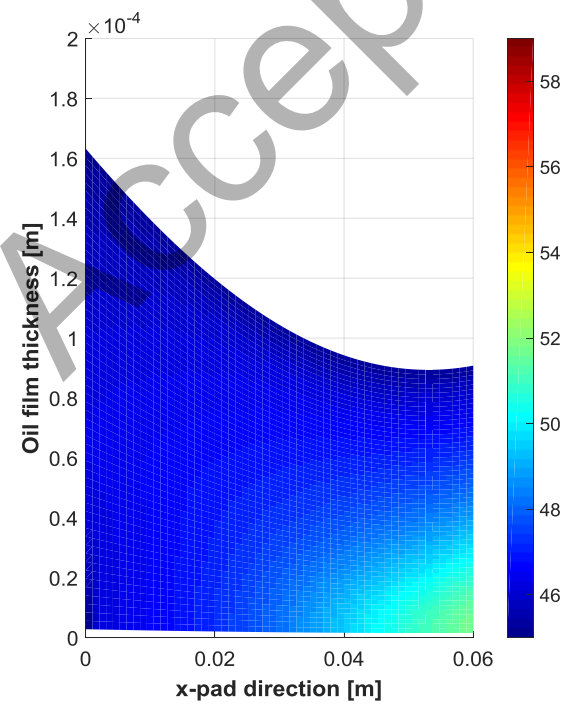

(e)

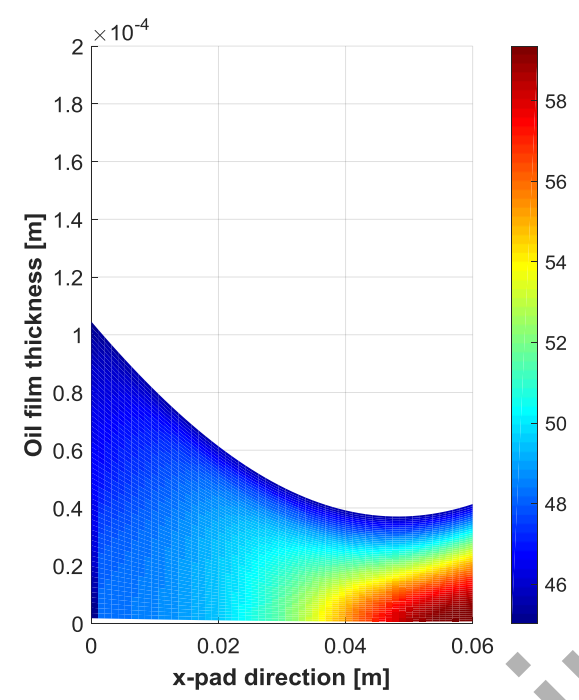

(b)

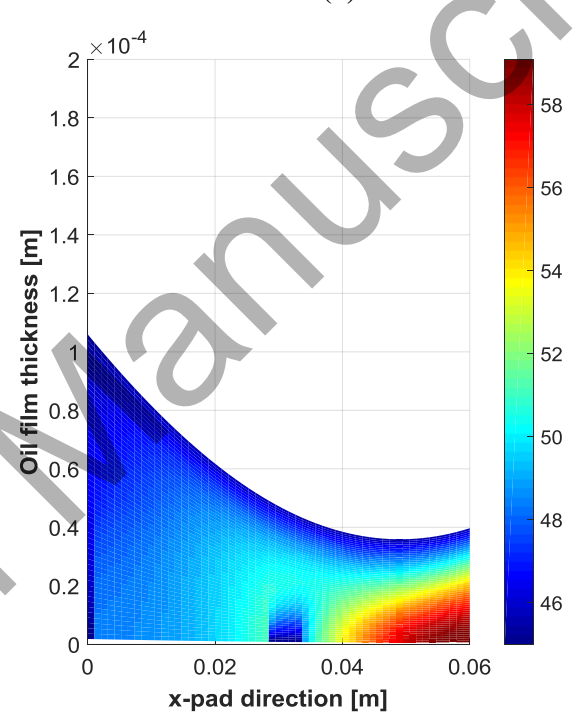

(d)

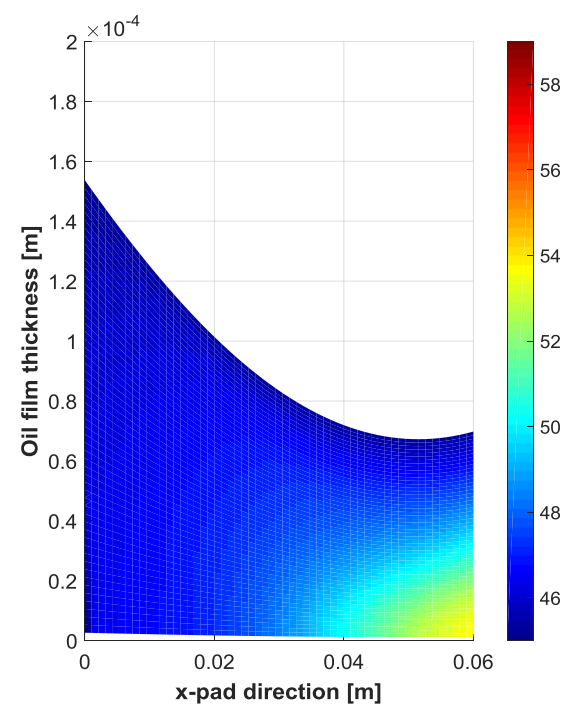

(f) 

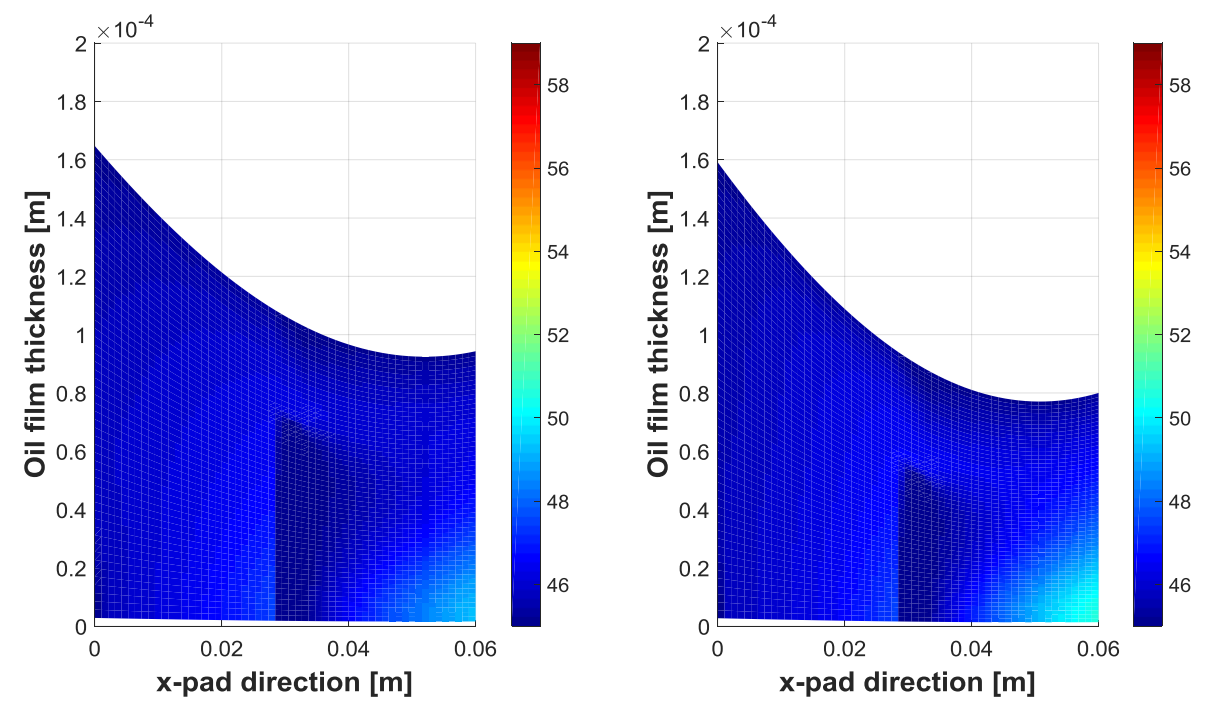

(g)

(h)

Figure 13. Results of oil film thickness and temperature profile for the cases tested: (a) Case 1, upper pad, (b) Case 1, lower pad; (c) Case 2, upper pad, (d) Case 2, lower pad; (e) Case 3, upper pad, (f) Case 3, lower pad; (g) Case 4, upper pad, (h) Case 4, lower pad. 


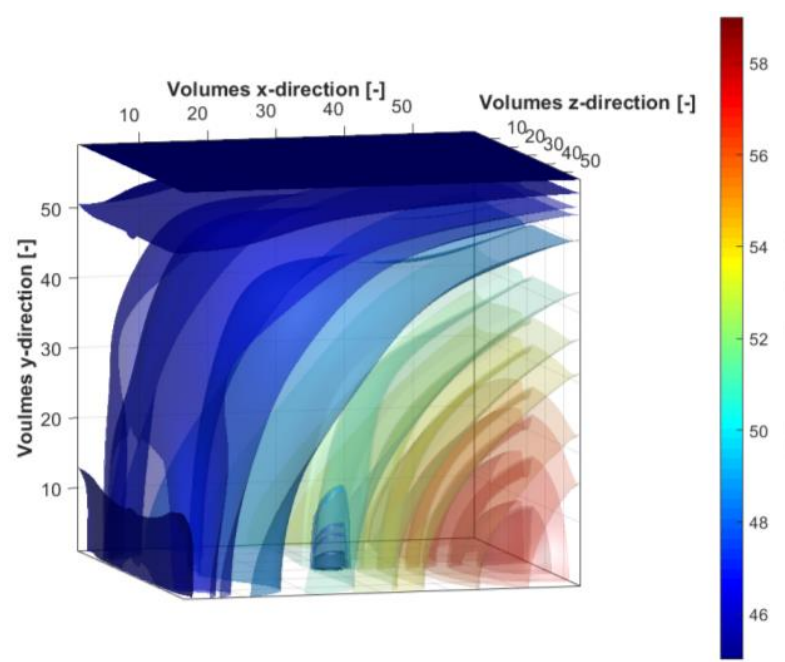

(a)

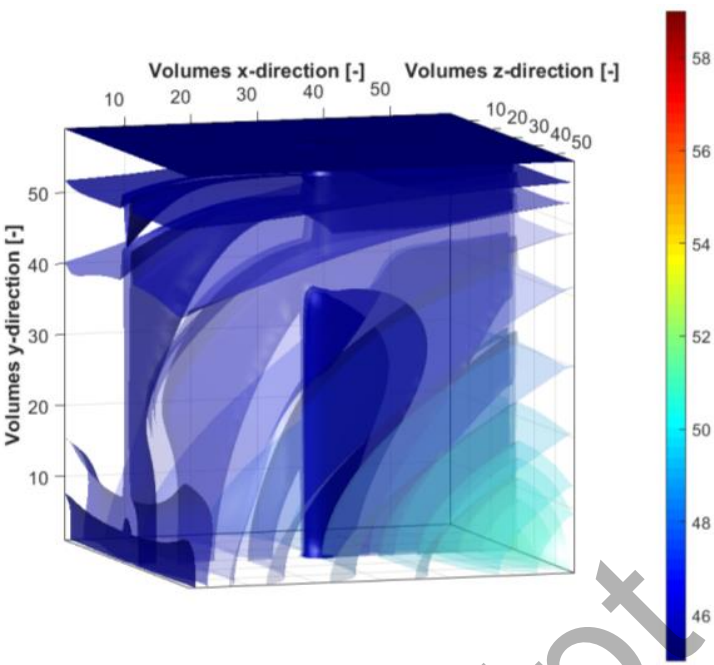

(b)

Figure 14. Results of iso-temperature surfaces for the 3D domain for case 2 (a) and case 4 (b). 
Table 1. TPJB geometrical dimensions, lubricant properties and operating conditions

\begin{tabular}{|c|c|c|c|}
\hline & Symbol & Value & Unit \\
\hline Injection orifice diameter & $d_{0}$ & 3 & {$[\mathrm{~mm}]$} \\
\hline Injection duct length & $l_{0}$ & 12 & {$[\mathrm{~mm}]$} \\
\hline Injection Pressure & $P_{i n j}$ & 0,10 & {$[$ bar $]$} \\
\hline Injection Temperature & $T_{\text {inj }}$ & $40-50$ & {$\left[{ }^{\circ}\right]$} \\
\hline Oil type & - & ISO VG22 & - \\
\hline Pad mass & $m_{\text {pad }}$ & 0.72 & {$[K g]$} \\
\hline Pad thickness & $h_{s}$ & 12 & {$[\mathrm{~mm}]$} \\
\hline Pad angular span & $\beta$ & 69 & {$\left[{ }^{\circ}\right]$} \\
\hline Pad radius & $R_{S}$ & 49.892 & {$[\mathrm{~mm}]$} \\
\hline Pad material & - & Brass & - \\
\hline Number of pads & - & 2 & - \\
\hline Load angle & - & On Pad & - \\
\hline Pivot material & - & Steel & - \\
\hline Pivot offset & - & 0.5 & - \\
\hline Shaft temperature & $T_{\text {shaft }}$ & 45 & {$\left[{ }^{\circ}\right]$} \\
\hline Bearing length & $L$ & 100 & {$[\mathrm{~mm}]$} \\
\hline Radial clearance & $C_{p}$ & 50 & {$[\mu m]$} \\
\hline Journal radius & $R$ & 49.692 & {$[\mathrm{~mm}]$} \\
\hline Mass of frame and journal & $m$ & 18.54 & {$[K g]$} \\
\hline Preload & $m_{p}$ & 0.76 & \\
\hline Oil specific heat capacity & $C_{f}$ & 1926 & {$[\mathrm{~J} /(\mathrm{Kg} . \mathrm{K})]$} \\
\hline Oil film density & $\rho$ & 879 & {$\left[\mathrm{Kg} / \mathrm{m}^{3}\right]$} \\
\hline Thermal conductivity & $k_{f}$ & 0.132 & {$[W /(m . K)]$} \\
\hline Distance to the center of the journal & $l_{1}$ & 0.21 & {$[\mathrm{~mm}]$} \\
\hline Distance to end of the frame & $l_{2}$ & 0.47 & {$[\mathrm{~mm}]$} \\
\hline
\end{tabular}


Table 2. Level of injection pressure and pivot flexibility for simulated cases.

\begin{tabular}{|c|c|c|}
\hline Cases & Oil Injection & Pivot Flexibility \\
\hline $\mathbf{1}$ & No & No \\
\hline $\mathbf{2}$ & $10 \mathrm{bar}$ & No \\
\hline $\mathbf{3}$ & No & $K=3.9 .10^{7} \mathrm{~N} / \mathrm{m}$ \\
\hline $\mathbf{4}$ & $10 \mathrm{bar}$ & $K=3.9 .10^{7} \mathrm{~N} / \mathrm{m}$ \\
\hline
\end{tabular}

